\title{
Behavior, Design, and Modeling of Structural Walls and Coupling Beams - Lessons from Recent Laboratory Tests and Earthquakes
}

\author{
John W. Wallace
}

\author{
(Received February 13, 2012, Revised February 20, 2012, Accepted February 20, 2012)
}

\begin{abstract}
Observed wall damage in recent earthquakes in Chile and New Zealand, where modern building codes exist, exceeded expectations. In these earthquakes, structural wall damage included boundary crushing, reinforcement fracture, and global wall buckling. Recent laboratory tests also have demonstrated inadequate performance in some cases, indicating a need to review code provisions, identify shortcomings and make necessary revisions. Current modeling approaches used for slender structural walls adequately capture nonlinear flexural behavior; however, strength loss due to buckling of reinforcement and nonlinear and shear-flexure interaction are not adequately captured. Additional research is needed to address these issues. Recent tests of reinforced concrete coupling beams indicate that diagonally-reinforced beams detailed according to ACI $318-11^{1}$ can sustain plastic rotations of about $6 \%$ prior to significant strength loss and that relatively simple modeling approaches in commercially available computer programs are capable of capturing the observed responses. Tests of conventionally-reinforced beams indicate less energy dissipation capacity and strength loss at approximately $4 \%$ rotation.
\end{abstract}

Keywords: testing, structural wall, coupling beam, modeling, detailing.

\section{Introduction}

Design and construction practice for special structural walls (ACI 318 designation) has evolved significantly since the system was introduced in the 1970's. Throughout the 1970s and 1980s, it was common to use so-called barbell-shaped wall cross sections, where a "column" was used at each wall boundary to resist axial load and overturning, along with a narrow wall web. In the late 1980s and early 1990s, use of rectangular wall cross sections became common to produce more economical designs. Use of walls with rectangular cross sections is common in many countries, including Chile and New Zealand. Although use of walls with boundary columns is still common in Japan, based on information available in the literature, the AIJ Standard for "Structural Calculations of Reinforced Concrete Buildings" was revised in 2010 to show RC walls with rectangular cross-sections. Engineers around the world have pushed design limits in recent years, optimizing economy and design, and in many practices producing walls with higher demands and more slender profiles than have been verified in past laboratory testing or field experience. The trend towards more slender profiles has been accelerated by use of higher concrete strengths.

\footnotetext{
${ }^{1)}$ Department of Civil and Environmental and Environmental Engineering, University of California, Los Angeles, Los Angeles, CA 90095, USA, *Corresponding Author; E-mail: wallacej@ ucla.edu

Copyright (c) 2012, Korea Concrete Institute. All rights reserved, including the making of copies without the written permission of the copyright proprietors.
}

Observed wall damage in recent earthquakes in Chile (2010) and New Zealand (2011), where modern building codes exist, exceeded expectations. In these earthquakes, structural wall damage included boundary crushing, reinforcement fracture, and global wall buckling. Recent tests of isolated structural walls in the US and tests of two, full-scale, 4-story buildings with high-ductility structural walls at E-Defense in December 2010 provide vital new data. A particularly noteworthy aspect of these recent tests is the failure of relatively thin wall boundaries to develop ductile behavior in compression, even though they complied with building code provisions and recommendations of ACI and AIJ.

The observed performance following recent earthquakes and in recent laboratory tests suggests strongly that the problems observed are not isolated and that analysis and design provisions need to be reassessed. In particular, the quantity and configuration of transverse reinforcement required at wall boundaries needs to be reassessed to address issues associated with wall thickness, slenderness, axial load, and configuration, as well as expected displacement demands and load history. Preliminary studies indicate that greater amounts of transverse reinforcement may be required for thin walls or walls with large cover and that tighter spacing of transverse reinforcement may be required to suppress buckling of vertical reinforcement, especially for walls with light axial load or walls with flanges. These issues apply to both high ductility (ACI Special) and moderate ductility (ACI Ordinary) walls.

The observed wall performance also raises important questions and challenges related to nonlinear modeling of structural walls and coupling beams, commonly accomplished using either beamcolumn models with plastic hinges or fiber models with uniaxial 
material relationships. Beam-column element models with plastic hinges are simple and provide reasonably good estimates of global and average local responses; however, they have various drawbacks, such as accounting for migration of the neutral axis, incorporating in- and out-of-plane coupling, and accounting for stiffness variation with axial load. ${ }^{2}$ Fiber and fiber-type models, such as the multiple-vertical-line-element model, where flexural response is simulated by a series of uniaxial elements (or macrofibers) along with the assumption that plane sections remain plane after loading, address these shortcomings and provide a better framework for incorporating more complex behaviors. However, fiber models also have drawbacks, such as added complexity, convergence issues, and results that are sensitive to meshing. More complex modeling approaches based on multi-axial material models are generally not used for design, and are not addressed here.

Fiber and beam-column models have been incorporated into research oriented programs such as opensees (2009) and wall as practice-oriented programs used for performance-based design such as CSI Perform 3D ${ }^{76}$. Considerable effort has focused on validating and calibrating these models for axial-flexural behavior, ${ }^{2-6}$ shear behavior, ${ }^{7}$ anchorage/splice behavior, ${ }^{8}$ and axial failure. ${ }^{9-11}$ More Recent research has focused on accounting for interaction (or coupling) between axial-flexural and shear responses, ${ }^{12-15}$ with various modeling approaches proposed, e.g., fiber/section based models, ${ }^{7,16-18}$ strut models, ${ }^{19}$ and simplified models using analyti$\mathrm{cal}^{20}$ or experimental results. ${ }^{21}$ Wall test programs focused on providing data for validation of shear-flexure interaction models for intermediate wall aspect ratios have recently been completed. ${ }^{22}$

Various testing programs have been carried out to assess the load - deformation behavior of coupling beams. ${ }^{23-30}$ Primary test variables in these studies were the ratio of the beam clear span to the beam total depth (commonly referred to as the beam aspect ratio) and the arrangement of the beam reinforcement. In a majority of these studies, the load - deformation behavior of low-aspect ratio beams ( 1.0 to 1.5 ) constructed with beam top and bottom longitudinal reinforcement were compared with beams constructed with diagonal reinforcement. Concrete compressive strengths for most tests were around $4 \mathrm{ksi}(\sim 25$ to $30 \mathrm{MPa})$. Although these tests provided valuable information, they do not address issues for current tall building construction, where beam aspect ratios are typically between 2.0 and 3.5 and concrete strengths are in the range of 6 to $8 \mathrm{ksi}(\sim 40$ to $55 \mathrm{MPa})$. In addition, in none of the prior studies was a slab included as part of the test specimen; whereas the slab might restrain axial elongations and impact stiffness, strength, and deformation capacity. Recent studies $^{31-33}$ address many of these issues.

Nonlinear modeling of coupling beams has become important as the use of coupled core wall systems have become more common. ${ }^{34,35}$ For coupling beams, important modeling parameters include effective bending stiffness $E_{c} I_{\text {eff }}$, allowable plastic rotation prior to significant lateral strength degradation, and residual strength. The effective bending stiffness for beams in ASCE 41-06 Table 6-4 was reduced to $0.3 E_{c} I_{g}$ to account for the added flexibility due to reinforcement slip/extension; ${ }^{36}$ however, modeling parameters in Table 6-18 for RC coupling beams were not changed. Verifying that the relatively simple modeling approaches commonly used for design adequately capture coupling beam load - deformation responses, as well as recommending parameters associated with unloading/reloading and pinching behavior, are important issues that have not been adequately investigated.

Given this background, the objectives of this paper are to review current wall and coupling beam test results and to identify issues that are not adequately addressed, both in terms of code design provisions and nonlinear modeling.

\section{Observed performance of structual walls \& coupling beams}

\subsection{Recent earthquake reconnaissance}

Recent earthquakes in Chile $\left(\mathrm{M}_{\mathrm{w}} 8.8\right.$, February 2010), New Zealand (February 2011, $\left.\mathrm{M}_{\mathrm{L}}=6.3\right)$, and Japan $\left(\mathrm{M}_{\mathrm{w}}\right.$ 9.0, March 2011) have provided a wealth of new data on the performance of modern buildings that utilize structural walls for the primary lateral-force-resisting system. Although complete building collapse was rarely observed, damage was widespread and generally exceeded expectations.

In 1996, Chile adopted a new code (NCh 433 . of 96$)^{37}$ based on ACI $318-95^{38}$ and produced an immense inventory of progressively more slender buildings corresponding essentially to the US reinforced concrete code provisions, except boundary element confinement was not required. The $2010 \mathrm{M}_{\mathrm{w}} 8.8$ earthquake caused serious damage to many of these buildings, including crushing/spalling of concrete and buckling of vertical reinforcement, often over a large horizontal extent of the wall (Fig. 1). Damage tended to concentrate over a relatively short height of one to three times the wall thickness, apparently because buckling of vertical bars led to concentration of damage. Closer inspection of the wall boundary regions (Fig. 1) revealed the relatively large spacing of hoops $(20 \mathrm{~cm})$ and horizontal web reinforcement $(20 \mathrm{~cm})$, as well as the 90-degree hooks used on hoops and horizontal web reinforcement, which may have opened due to concrete crushing and/or buckling of vertical reinforcement (Fig. 1(d)). Some of the failures are attributable to lack of closelyspaced transverse reinforcement at wall boundaries, which was not required by the Chilean code based on the good performance of buildings in the 1985 M7.8 earthquake; however, many of the failures are not yet understood, and many suggest that there are deficiencies in current US design provisions. ${ }^{39,40}$ In some cases, lateral instability (buckling) of a large portion of a wall section was observed (Fig. 2); prior to the Chile and New Zealand earthquakes, this global buckling failure had been primarily observed in laboratory tests. ${ }^{41}$ Detailed surveys conducted as part of ATC-94 ${ }^{42}$ indicate that global wall buckling was not driven by prior yielding in tension (as had originally been suspected based on past research $^{43-45}$ ) but instead was the result of lateral instability of previously crushed boundary zones. Furthermore, the ATC- $94^{42}$ study has been unable to establish through analysis the role of preemptive longitudinal bar buckling as a trigger for compression failure of lightly confined boundary zones. Laboratory testing is required to understand these behaviors; preliminary studies are underway in Chile and the US to investigate these issues.

The 2011 Christchurch earthquake ${ }^{46,47}$ shows many similar wall failures, suggesting the deficiencies observed in the 2010 Chile earthquake are not isolated (Fig. 3(a)). All of the walls depicted in Figs. 2 and 3 have either T-shaped (Figs. 2, 3(b)) or L-shaped (Fig. 3(a)) cross sections, which lead to large cyclic tension and com- 

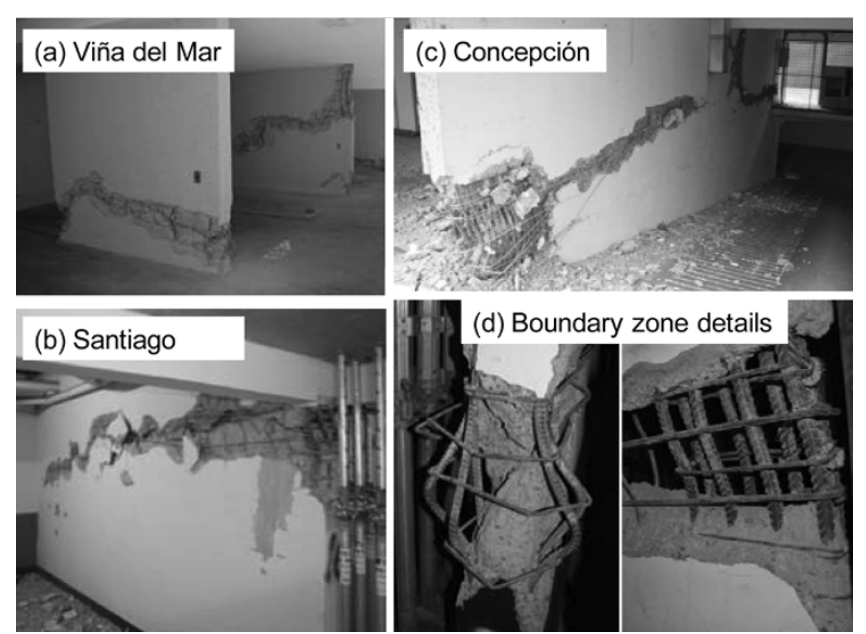

Fig. 1 Typical wall damage in Chile earthquake.

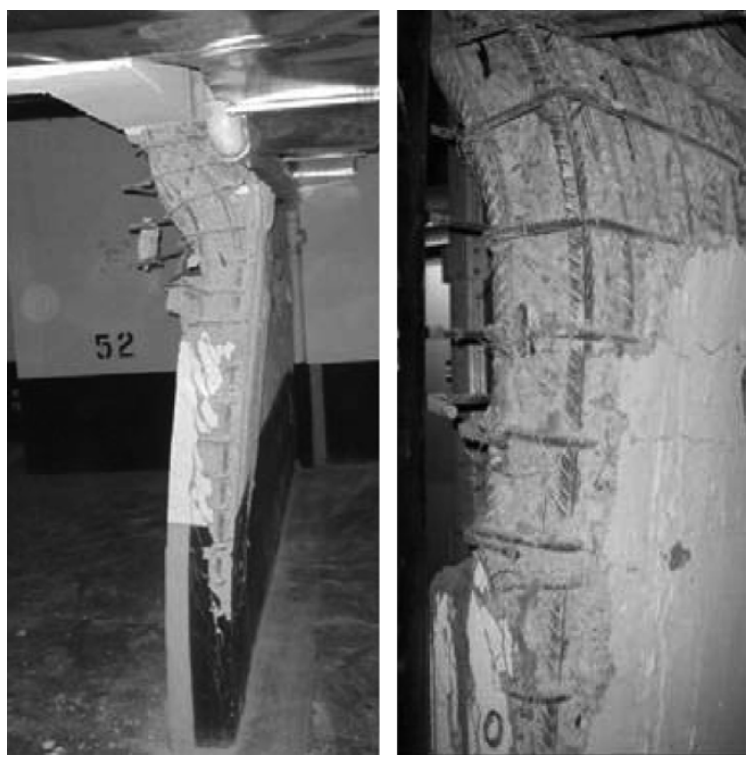

Fig. 2 Wall lateral instability.

pressive demands at the wall web boundary. ${ }^{48}$ The wall web boundaries are susceptible to out-of-plane buckling following cover concrete spalling. Although current ACI $318-11^{1}$ provisions require consideration of an effective flange width, the provisions do not restrict use of narrow walls and do not address this out-ofplane failure mode, i.e., there are no restrictions on wall thickness or wall slenderness. Failures of diaphragm-to-wall connections were observed in Christchurch, potentially contributing to the collapse of the several buildings. ${ }^{49}$ In Chile, typical buildings have a large number of walls that well-distributed in plane; therefore, diaphragm failures were not observed.

\subsection{Recent laboratory studies of conventional walls}

Recent laboratory testing of structural walls in the US has focused on addressing concerns related to behavior of walls with rectangular and T-shaped cross sections subjected to uniaxial and biaxial loading, ${ }^{50-52}$ walls with couplers and splices in the plastic hinge region, ${ }^{53,54}$ walls with higher shear demands, ${ }^{54-56}$ and walls with coupling beams..$^{32,33,57}$ All of these studies involved quasi-
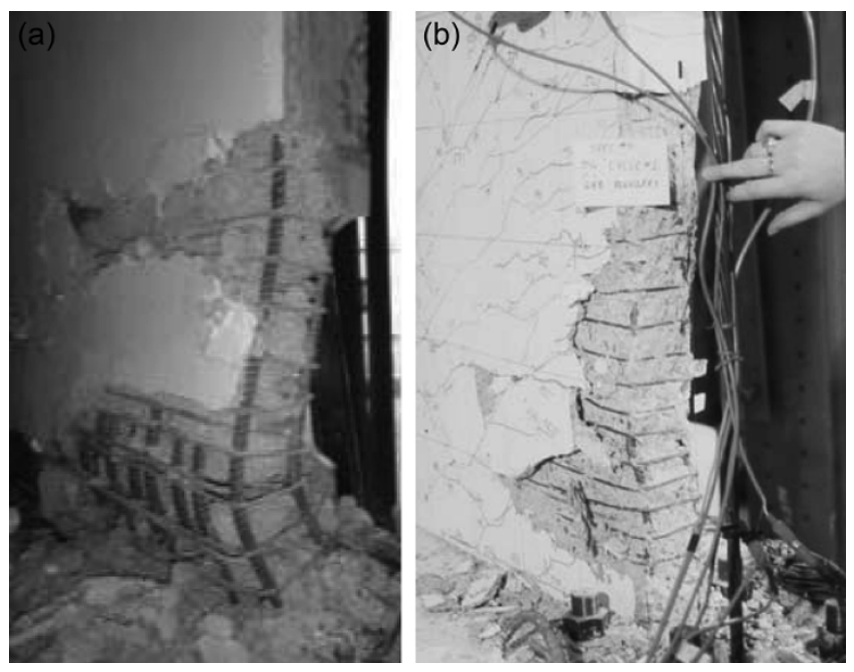

Fig. 3(a) Wall failure in 2011 Christchurch earthquake. ${ }^{49}$ Fig. 3(b) Specimen TW2 web boundary failure. ${ }^{41}$

static testing. Shake table testing of walls has been limited, except for 7-story "building slice" tests of walls with rectangular and Tshaped cross sections conducted by Panagiotou and Restrepo. ${ }^{58}$ The overwhelming majority of quasi-static and shake table tests conducted in Japan have been conducted on barbell-shaped walls and low-rise buildings with "wing walls", $59-61$ which are not common in the US. Only recently have the Japanese Building Standard Law and Architectural Institute of Japan recommendations been modified to allow the use of rectangular walls with boundary elements, but their use is not widespread.

Johnson $^{53}$ reports test results of isolated, slender $\left(\mathrm{h}_{\mathrm{w}} / \mathrm{l}_{\mathrm{w}}\right.$ and $\mathrm{Mu} /$ $\mathrm{V}_{\mathrm{u}} \mathrm{l}_{\mathrm{w}}=2.67$ ) cantilever walls to investigate the behavior of anchorage details for flexural reinforcement. Three walls were tested, one each with continuous (RWN), coupled (RWC), and spliced (RWS) vertical reinforcement. The wall cross sections were 6 in. $\times 90$ in. $(152.4 \mathrm{~mm} \times 2.29 \mathrm{~m})$, and the walls were subjected to horizontal lateral load approximately $20 \mathrm{ft}$ or $6.1 \mathrm{~m}$ above the base. Although the wall cross-sections were rectangular, different amounts of boundary vertical reinforcement were used to simulate the behavior of T-shaped wall cross sections; 4-\#6 $\left(\mathrm{d}_{\mathrm{b}}=19 \mathrm{~mm}\right)$ and 2-\#5 $\left(\mathrm{d}_{\mathrm{b}}=15.9 \mathrm{~mm}\right)$ at one boundary and 8-\#9 $\left(\mathrm{d}_{\mathrm{b}}=28.7 \mathrm{~mm}\right)$ at the other boundary. Horizontal wall web reinforcement, of \#3 @ 7.5 in. or $\rho_{\mathrm{t}}=0.0049\left(\mathrm{~d}_{\mathrm{b}}=9.5 \mathrm{~mm} @ 19 \mathrm{~cm}\right)$, was selected to resist the shear associated with the expected moment strength (including overstrength). Wall web vertical reinforcement consisted of \#4@18 in. or $\rho_{v}=0.0037\left(d_{b}=12.7 \mathrm{~mm} @ 45.7 \mathrm{~cm}\right)$. It is noted that the $18 \mathrm{in} .(45.7 \mathrm{~cm})$ spacing of vertical web reinforcement is the maximum spacing allowed by ACI 318-11 21.9.2.1. It is questionable whether such a large spacing $(45.7 \mathrm{~cm})$ in such a thin wall $(15.2 \mathrm{~cm})$, satisfies the intent of R21.9.4, which states that wall we reinforcement should be "appropriately distributed along the length and height of the wall... should be uniform and at a small spacing." Lateral load versus top lateral displacement relations for RWC and RWS are plotted in Fig. 4(a); since results for RWC and RWN are very similar. For RWC, the wall reached rotations exceeding +0.035 (\#5 in tension) and -0.02 (\#9 in tension), whereas for RWS, the wall reached rotations of approximately +0.02 (\#5 in tension) and -0.012 (\#9 in tension). Damage was concentrated at a single, large crack at the foundation-wall inter- 


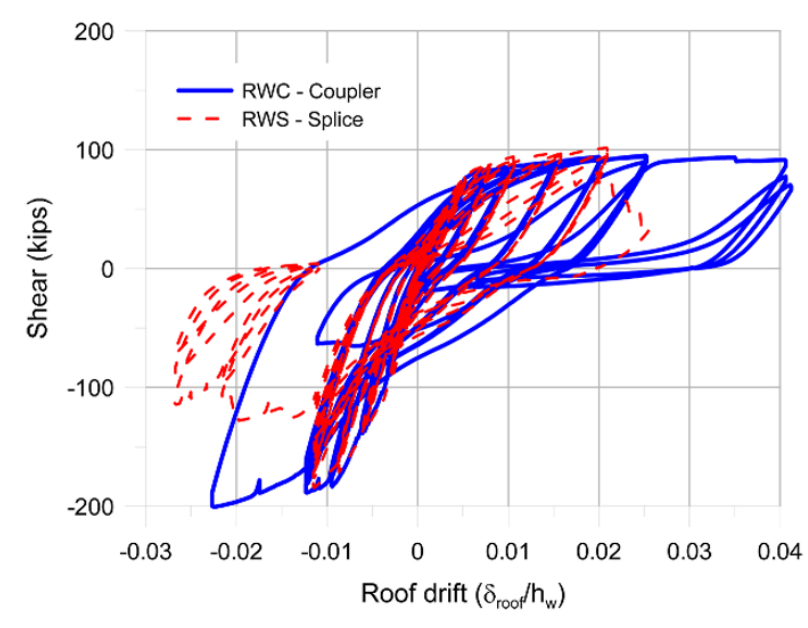

Fig. 4(a) Load-displacement relations.

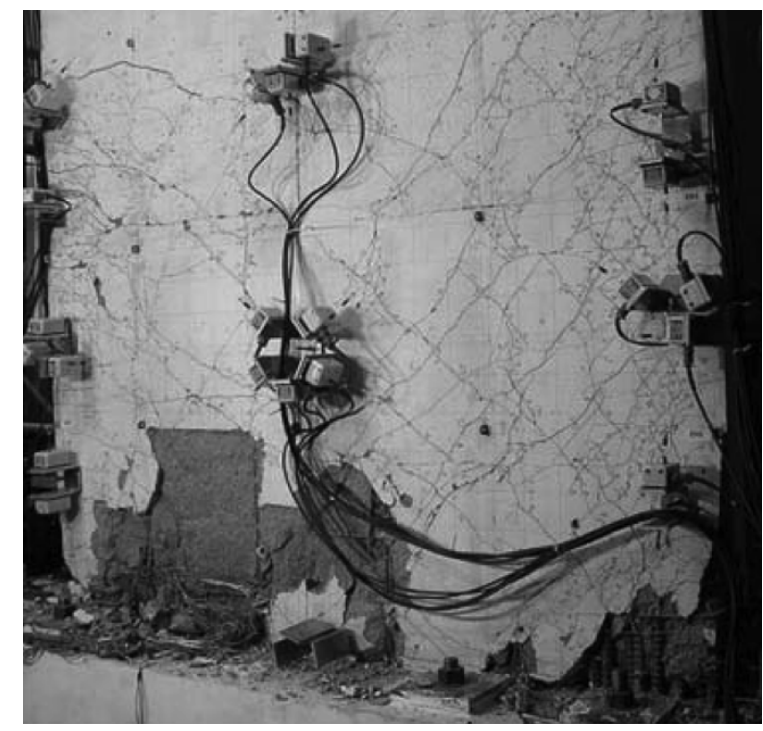

Fig. 4(b) Wall damage at end of test (RWS).

face, which accounted for about 0.015 of the top rotation of 0.02 . It is noted that the applied shear is close to or exceeds the web shear friction capacity $V_{n}$ of the walls, depending on the direction of the applied load and the value assumed for the coefficient of friction. Significant horizontal cracking also was observed for specimens RWN and RWC, suggesting that the quantity (and large spacing) vertical web reinforcement was insufficient to restrain sliding between the wall boundaries. Damage concentrated at the foundation-wall interface for specimen RWS (Fig. 4(b)). However, the test results do indicate adequate performance in the case of the coupler and that the presence of the splice significantly reduced the wall lateral deformation capacity.

Tests of walls with splices also were conducted by Birely et al. ${ }^{54}$ The test specimens were roughly one-half scale replicas of the bottom three stories of a ten-story wall (Fig. 5(a)). Base shear versus 3rd story (top) displacement plots are shown in Fig. 5(b) for three of the tests, PW1 (splice, $\mathrm{M}_{\mathrm{b}}=0.71 h_{w} V_{b}$ ), W2 (splice, $\mathrm{M}_{\mathrm{b}}=$ $0.50 h_{w} V_{b}$ ), and W4 (no splice, $\mathrm{M}_{\mathrm{b}}=0.50 h_{w} V_{b}$ ). Design wall shear stresses were $0.23,0.33$, and $0.33 \sqrt{f_{c}^{\prime} M P a} \mathrm{MPa}$ for $\mathrm{W} 1, \mathrm{~W} 2$, and $\mathrm{W} 4$, respectively (equivalent to $0.7,0.9$, and $0.9 V_{n}$ ). The $\# 4$ $\left(\mathrm{d}_{\mathrm{b}}=12.7 \mathrm{~mm}\right)$ boundary bars were lapped $0.61 \mathrm{~m}$, with spacing of boundary transverse reinforcement of $51 \mathrm{~mm}\left(\mathrm{~s} / \mathrm{d}_{\mathrm{b}}=4\right)$. The test

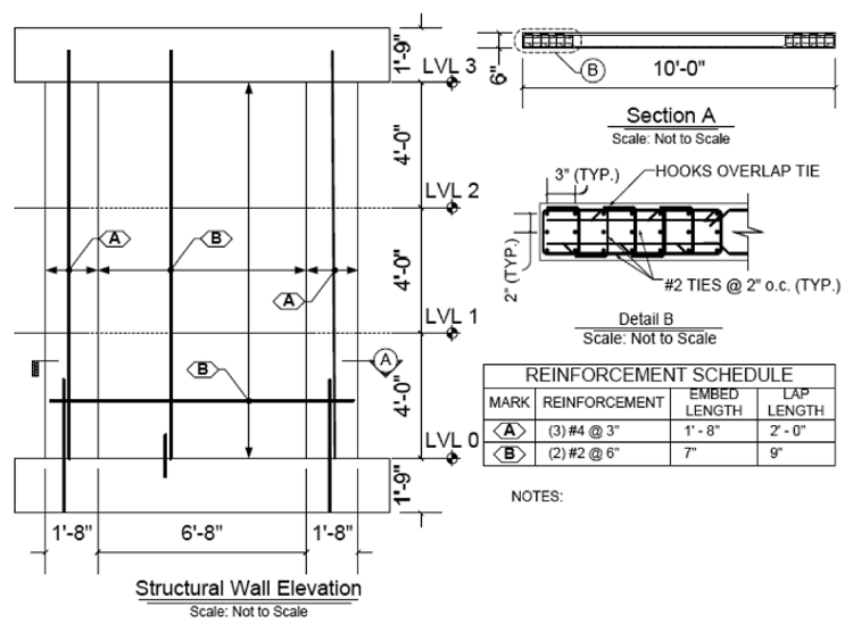

Fig. 5(a) NEESR UW wall tests.

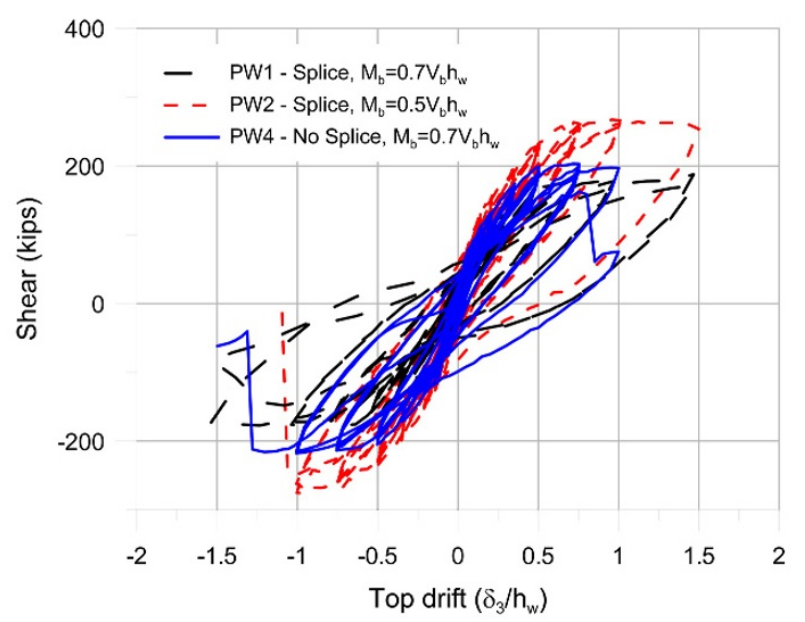

Fig. 5(b) Base shear vs drift.

with lower shear stress was reasonably ductile, achieving $1.08 \mathrm{M}_{\mathrm{n}}$ and a 3rd story lateral drift of $1.5 \%$ prior to strength loss; however, test PW4, with no splice, reached only $1.0 \%$ lateral drift at the third story (top) prior to strength loss. For all tests with splices, damage initiated with buckling of the interior bar at the wall edge (Fig. 6(a)) and then concentrated at the top of the splices (Fig. $6(\mathrm{~b}))$, whereas damage was concentrated at the foundation-wall interface for test PW4 with no splice (Fig. 6(c)). Even without consideration of the elastic deformations over the top seven stories not included in the test, deformation capacities of the walls are less than expected, especially for PW4, with no splice.

Nagae et al. ${ }^{62}$ summaries important details for NIED (EDefense) tests on two 4-story buildings, one conventionally reinforced and the other using high-performance RC construction, both with rectangular wall cross sections (Fig. 7a). The conventionally reinforced wall had confinement exceeding US requirements, with axial load of approximately $0.03 A_{g} f_{c}^{\prime}$, yet the compression boundary zone sustained localized crushing and lateral buckling (Fig. 7(b), following Kobe 100\% motion). The base overturning moment versus roof displacement responses are plotted in Fig. 8; base rotations are slightly less than the roof drift ratio (e.g., for Kobe $100 \%$, the base rotation measured over $0.27 l_{w}$ is a little more than 0.02). Following crushing of boundary regions, sliding shear responses increased substantially during the Kobe 


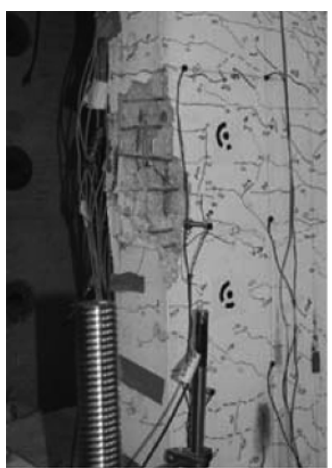

(a) PW2 @ 1.0\% drift

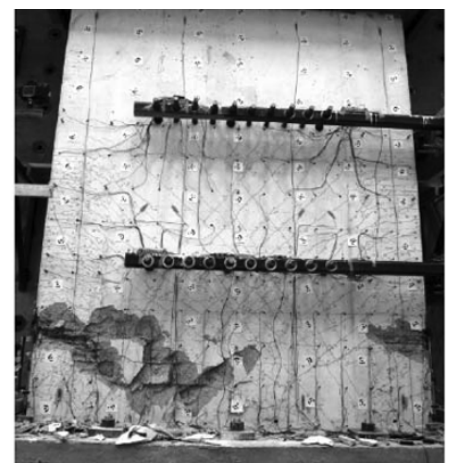

(b) PW2 end of test

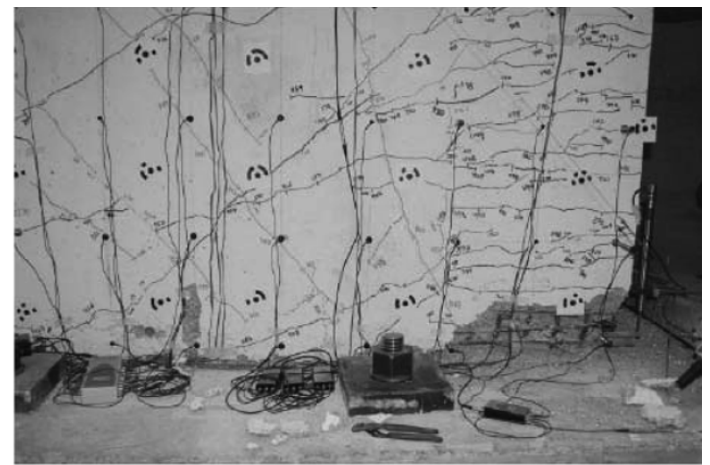

(c) PW4 @ 1.0\% drift

Fig. 6 Wall damage: (a) PW2 @ 1.0\% drift; (b) PW2 end of test; (c) PW4 @ 1.0\% drift.

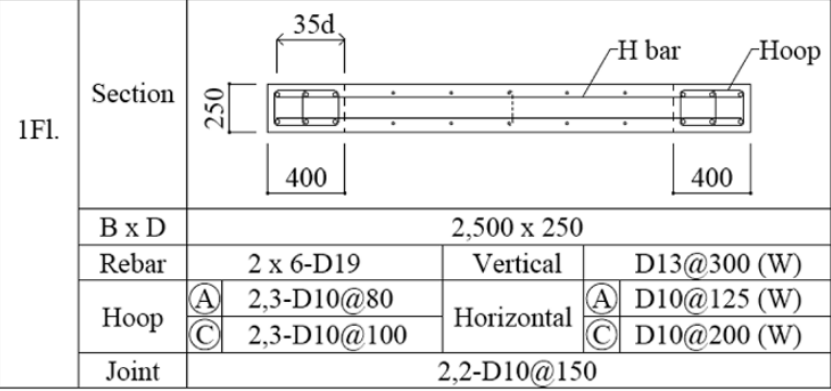

Fig. 7(a) RC conventional wall. ${ }^{62}$

100\% test (Fig. 8). Sliding displacements in the Takatori $60 \%$ test reached the limits of the sensor, $+45 \mathrm{~mm}$ and $-60 \mathrm{~mm}$ with peak shear of $+/-2000 \mathrm{kN}$. It is noted that the relatively large clear cover over the boundary longitudinal bars was used $(\sim 40 \mathrm{~mm})$ and the boundary transverse reinforcement was insufficient to maintain the boundary compressive load following cover spalling. It is noted that the crushing/spalling of the boundary region was accompanied by lateral buckling of the compression zone, as was observed in Chile and New Zealand (Fig. 2). It is yet unclear what role biaxial loading had on the observed wall damage, this issue is still being studied; however, it is plausible that the susceptibility of the wall to lateral instability was impacted by biaxial loading.

The pre-NEESR tests conducted at NEES@Minnesota ${ }^{51,52,63}$ studied the role of biaxial loading by subjecting cantilever walls with T-shaped cross sections to biaxial loading and comparing

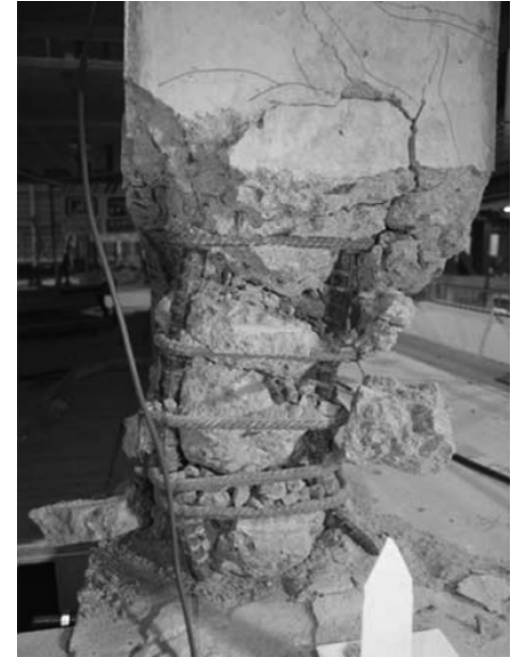

Fig. 7(b) Wall damage.

their results with similar tests subjected to in-plane loading. ${ }^{41}$ The 6 in $(152.4 \mathrm{~mm})$ thick walls exhibited rotations over the first story $\left(\mathrm{h}_{\mathrm{s}}=0.8 l_{w}\right)$ of approximately 0.02 prior to lateral strength degradation. Their findings suggest that analytical models validated previously for in-plane loading of walls adequately captured the measured responses for combined in- and out-of-plane loading. However, based on video and post-test observations, damage at wall boundaries of the conventional reinforced concrete building tested on the E-Defense shaking table may have been influenced
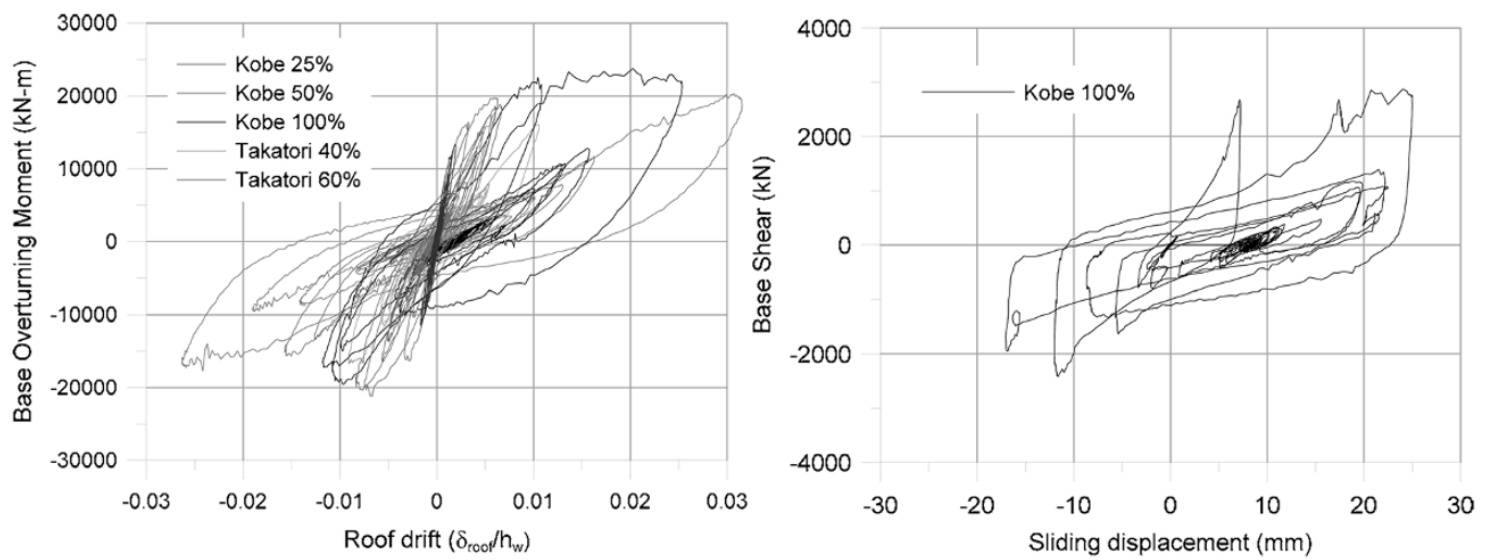

Fig. 8 RC conventional building responses (structural wall direction). 
by simultaneous in-plane and out-of-plane responses. The New Zealand Royal Commission report ${ }^{47}$ raises the issue of biaxial loading as a possible contributing factor to the unexpected wall damage in the February 2011 earthquake. This issue has not been adequately studied, and the issue is complicated by the observation that out-of-plane failures are observed at wall boundaries for in-plane loads alone.

\subsection{Recorded ground motions}

Response Spectra computed using ground motions recorded in recent earthquakes have significantly exceeded values used for design. For example, spectra for records in Chile ${ }^{64}$ and Christchurch $^{49}$ significantly exceed values used for design (Fig. 11). For Chile, many buildings are designed for the Soil II spectrum, whereas spectral ordinates are generally 2 to 6 times the values for Soil II over a broad period range. Given such large demands it is important to re-evaluate how displacement demands influence design requirements for structural walls.

\subsection{Coupling beam tests}

Recent tests of eight one-half scale coupling beams focused on assessing detailing and modeling parameters for coupling beam configurations common for taller buildings, including the influence of reinforced and post-tensioned slabs. A brief summary of these studies is presented here, with more information available in Naish $^{31}$ and Naish et al. ${ }^{65}$ Beams with transverse reinforcement provided around the bundles of diagonal bars (referred to as "diagonal confinement") were designed according to ACI 318-05 S21.7.7.4, whereas beams with transverse reinforcement provided around the entire beam cross section (referred to as "full section confinement") were designed according to ACI 318-08 S21.9.7.4 (d). Three test specimens with aspect ratio of 2.4 were constructed with 4" (101.6 mm)-thick slabs. CB24F-RC contained a slab reinforced with \#3 bars @12" spacing ( $d_{b}=9.5 \mathrm{~mm} @ 304.8 \mathrm{~mm}$ ), on the top and bottom in the transverse direction, and on the top only in the longitudinal direction, without post-tensioning strands. CB24F-PT and CB24F-1/2-PT both contained a similar reinforced-concrete slab, but also were reinforced with $3 / 8$ " (9.5 mm) 7-wire strands.

Load-deformation responses of CB24F and CB24D are very similar over the full range of applied rotations (Fig. 12(a)); similar results were obtained for 3.33 aspect ratio tests. Notably, both beams achieve large rotation $(\sim 8 \%)$ without significant degradation in the lateral load carrying capacity, and the beams achieve shear strengths of 1.25 and 1.17 times the ACI nominal strength. The shear strength of CB24D degraded rapidly at around $8 \%$ rotation, whereas CB24F degraded more gradually, maintaining a residual shear capacity of $\sim 80 \%$ at rotations exceeding $10 \%$. The test results indicate that the full section confinement option of ACI 318-08 provides equivalent, if not improved performance, compared to confinement around the diagonals per ACI 318-05. Diagonal crack widths for the full section confinement were generally less than for diagonal confinement.

Four beams with aspect ratio of 2.4 were tested to assess the impact of a slab on load-deformation responses. CB24F did not include a slab, whereas CB24F-RC included an RC slab, and CB24F-PT and CB24F-1/2-PT included PT slabs (with 150 psi (1.03 MPa) of prestress). Load-displacement responses of CB24F$\mathrm{RC}$ vs. CB24F-PT are compared in Fig. 12(b). The plots reveal that the slab increases the shear strength; however, this strength increase can be accounted for by considering the increase in nominal moment strength due to the presence of the slab and the pre-

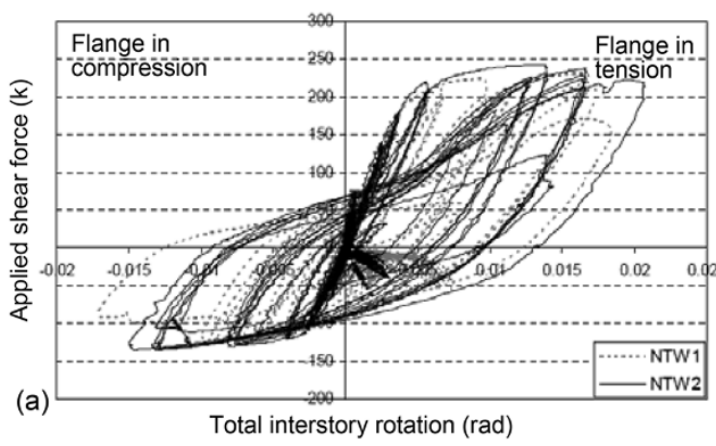

Fig. 10 Load vs displacement relations:

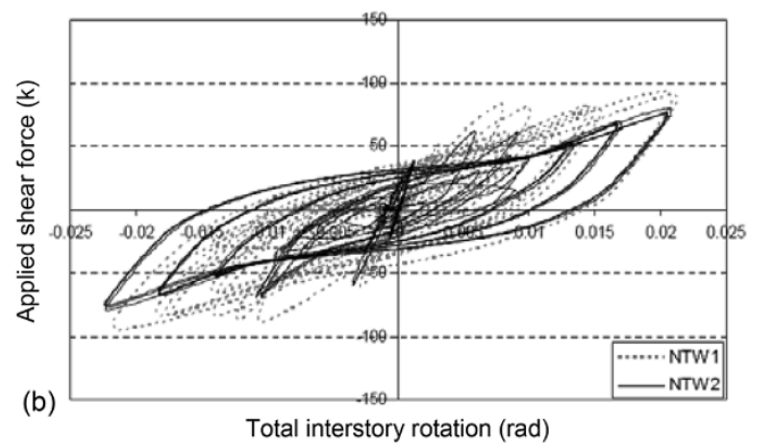

(a) web direction; (b) Flange direction. ${ }^{63}$
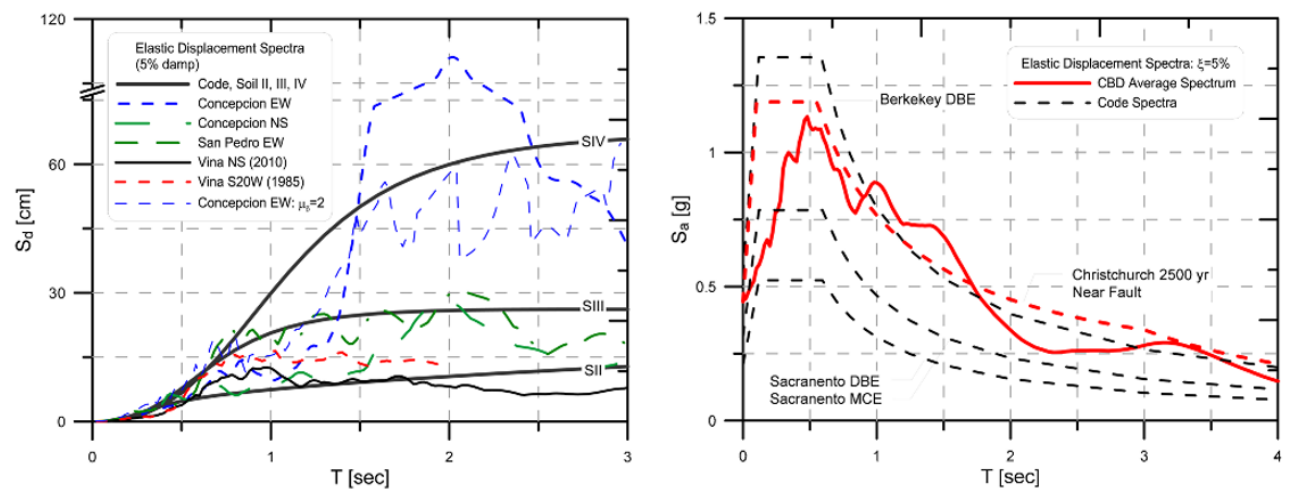

Fig. 11 Spectra from recent large earthquakes. 

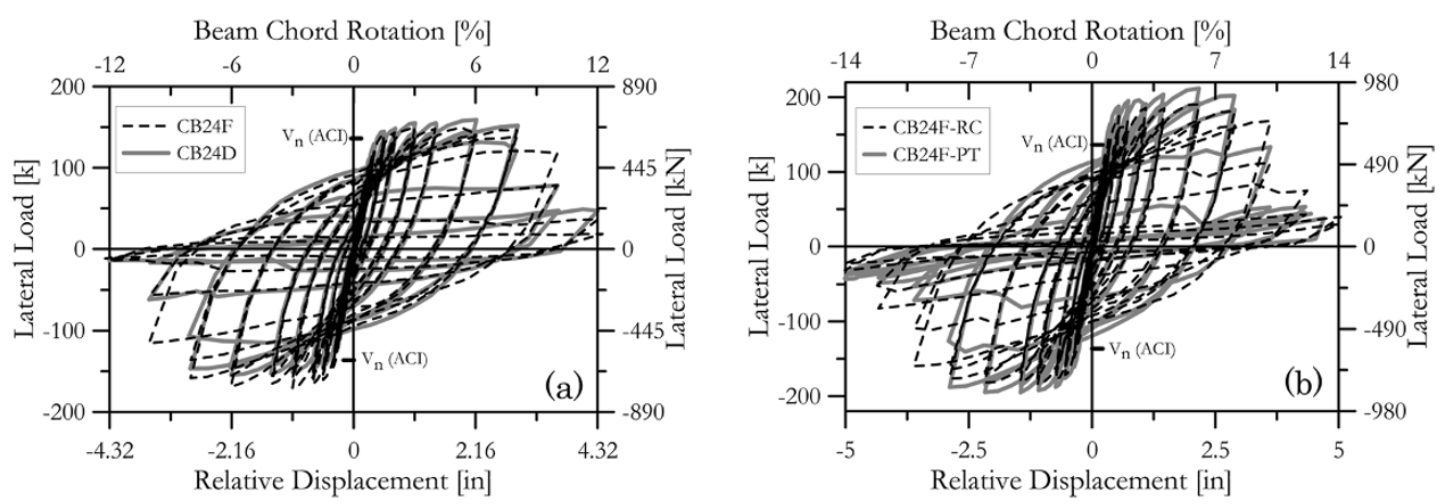

Fig. 12 Load - displacement relations for coupling beams without (a) and with (b) slabs.

stress. The peak loads for beams CB24F-RC vs. CB24F-PT correspond to shear stresses of $13.0 \sqrt{f_{c}^{\prime}} A_{c w}$ psi $\left(1.08 \sqrt{f_{c}^{\prime}} A_{c w} M P a\right)$ and CB24F-RC $11.8 \sqrt{f_{c}^{\prime}} A_{c w}$ psi $\left(0.98 \sqrt{f_{c}^{\prime}} A_{c w} M P a\right)$, respectively. The presence of a slab (RC or PT) restrains axial growth prior to yield, leading to modestly higher stiffness; however, the secant stiffness values following yield for beams with and without slabs are very similar and significant strength degradation for all beams occurs at approximately the same rotation $(8 \%)$. This increase in strength is primarily due to the axial force applied to the specimen by the tensioned strands, and increased the nominal moment strength. Between $8 \%$ and $10 \%$ rotation, strength degradation is more pronounced for CB24F-PT than CB24F-RC, with $30 \%$ reduction for CB24F-PT vs. $10 \%$ for CB24F-RC, possibly due to the presence of pre-compression.

A 3.33 aspect ratio beam with longitudinal beam reinforcement, referred to as a "Frame Beam" or FB33, was tested to assess the impact of providing straight bars as flexural reinforcement instead of diagonal bars in beams with relatively low shear stress demand $\left(<4.0 \sqrt{f_{c}^{\prime}}\right.$ psi; $\left.0.33 \sqrt{f_{c}^{\prime}} \mathrm{MPa}\right)$. A plot of load vs. deformation for FB33 (Fig. 13(a)) indicates that plastic rotations greater than $4 \%$ can be reached prior to strength degradation. These results correspond well with prior test results ${ }^{27}$ (Fig. 13(b)) on similarly sized beams, which achieved maximum shear stresses of about $4.7 \sqrt{f_{c}^{\prime}}$ $\left(0.39 \sqrt{f_{c}^{\prime}} \mathrm{MPa}\right)$ and plastic chord rotations greater than $3.5 \%$. Compared to a similar beam with diagonal reinforcement and fullsection confinement (CB33F), or diagonal confinement (CB33D), FB33 experiences more pinching in the load-deformation plot, indicating that less energy is dissipated. As well, the beams with diagonal reinforcement exhibited higher ductility, reaching plastic rotations exceeding $7 \%$ prior to strength degradation, versus approximately $4 \%$ for frame beams. The results indicate that use of longitudinal reinforcement for coupling beams, which are much easier to construct, is appropriate provided shear stress demands are less than approximately 5.0 $\sqrt{f_{c}^{\prime}}\left(0.42 \sqrt{f_{c}^{\prime}} \quad \mathrm{MPa}\right)$ and total rotation demands are less than approximately $4 \%$.

\subsection{Summary}

Wall performance in recent earthquakes and laboratory tests raises a number of design concerns. In Chile, brittle failures at wall boundaries were likely influenced by the level of axial stress (possibly leading to compression failures), the larger than expected displacement demands, the use of unsymmetric (or flanged) wall cross sections, and the lack of closely-spaced transverse reinforcement at wall boundaries. A particularly noteworthy aspect of recent tests ${ }^{57,62,66}$ is the failure of relatively thin wall boundaries to develop ductile behavior in compression, even though they complied with ACI 318 special boundary element requirements, as well as Japan Standard Building Law and AIJ (2010) requirements. Recent tests to investigate the role of splices within the plastic hinge region of structural walls suggest that splices will substantially reduce wall inelastic deformation capacity. Given these observations, current ACI 318-11 ${ }^{1}$ code provisions for Special Structural Walls are reviewed to identify possible concerns and to suggest changes that could be implemented to address these concerns.

Results from recent tests on diagonally- and longitudinally-reinforced coupling beams provide valuable new data to assess stiffness, detailing, and modeling requirements. The tests indicate that "full section" confinement is as effective as diagonal confinement, slab impacts on stiffness and nominal strength are modest, and beams with longitudinal reinforcement exhibit less energy dissipation and total rotation capacity compared to beams with diagonal reinforcement. New detailing provisions in ACI 318-08 were introduced based, in-part, on these test results.

\section{ACI 318 Chapter 21 provisions for special structural walls \& coupling beams}

Provisions for "Special Structural Walls" are contained in ACI 318-11 \$21.9 and include provisions for Reinforcement (21.9.2), Shear Strength (21.9.4), Design for Flexural and Axial Loads (21.9.5), and Boundary Elements of Special Structural Walls (21.9.6). In light of the preceeding discussion, key aspects of these provisions are reviewed and areas of concern are noted. In many cases, insufficient information is available to develop comprehensive requirements and comments provided here are meant to inform.

\subsection{Reinforcement and splices}

A single curtain of web reinforcement is allowed if wall shear stress is less than $0.17 \sqrt{f_{c}^{\prime} M P a} M P a$. This provision is acceptable for squat walls with low shear stress (e.g., walls with aspect ratio less than 1.5); however, for slender walls where buckling of boundary vertical reinforcement and lateral instability are more likely due to significant tensile yielding of reinforcement under cyclic loading, two curtains should always be used. This recommendation applies to both Special Structural Walls (high ductility) and Ordinary Structural Walls (moderate ductility). 

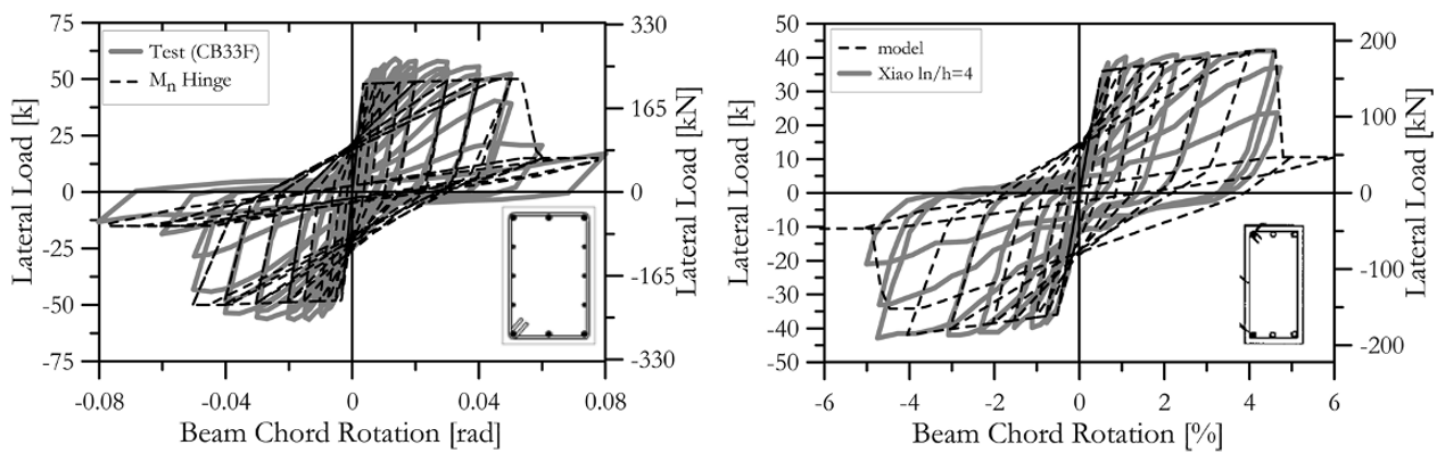

Fig. 13 Load - displacement relations for frame beams.

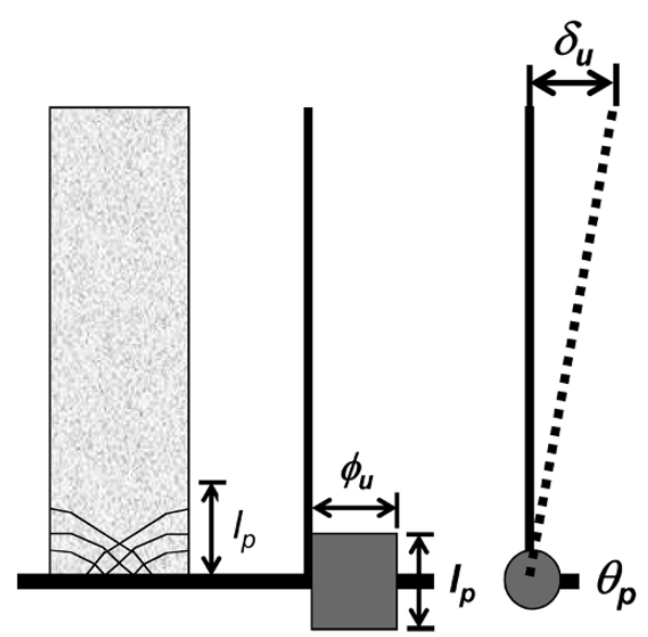

Fig. $14 \mathrm{ACl} 318-11 \S 21.9 .6 .2$ model.

Recent laboratory tests have identified that wall deformation capacity may be compromised in cases where splices exist within the wall critical section (plastic hinge) because nonlinear deformations are concentrated outside of the splice region, either at the wall-foundation interface (large moment gradient) ${ }^{53}$ or above the splice (nearly uniform wall moment). ${ }^{54}$ Given these results, it is questionable whether boundary vertical reinforcement should be lapped spliced within the plastic hinge region. Test results did indicate that use of ACI 318-11 Type II couplers performed adequately. The option of staggering splices is not addressed here.

\subsection{Design displacement and plastic hinge length}

The model used to develop ACI 318-11 §21.9.6.2 provisions is shown in Fig. 14. Given this model, the design displacement $\delta_{u}(A C I) \equiv \delta_{x}=C_{d} \delta_{e} / I(A S C E 7)$ is related to local plastic hinge rotation $\theta_{p}$ and extreme fiber compressive strain $\varepsilon_{c}$ as:

$$
\theta_{p}=\frac{\delta_{u}}{h_{w}} ; \theta_{p}=\left(\phi_{u}=\frac{\varepsilon_{c}}{c}\right)\left(l_{p}=\frac{l_{w}}{2}\right) \quad \therefore \varepsilon_{c}=2\left[\frac{\delta_{u}}{h_{w}}\right]\left[\frac{c}{l_{w}}\right]
$$

Where $l_{p}$ is the plastic hinge length, $h_{w}$ is the wall height, $c$ is the neutral axis depth for $\left(M_{n}, P_{u, \max }\right)$, and $l_{w}$ is the wall length. If the compressive strain exceeds a limiting value, typically taken as 0.003 , then special transverse reinforcement is required. In ACI 318-11 Equation (21-8), Equation (1) is rearranged to define a limiting neutral axis depth versus a limiting concrete compressive strain as:

$$
c_{\text {limit }}=\frac{0.003 l_{w}}{2\left(\delta_{u} / h_{w}\right)}=\frac{l_{w}}{667\left(\delta_{u} / h_{w}\right)} \approx \frac{l_{w}}{600\left(\delta_{u} / h_{w}\right)}
$$

In this approach, it is obvious that the result is sensitive to the values used for the design displacement and the plastic hinge length. Revised formulations, using a detailed displacement-based design approach ${ }^{67}$ and a plastic hinge length that varies with wall thickness $\left(l_{p}=a t_{w}\right.$ as suggested by Wallace, ${ }^{39}$ produces the following more comprehensive relation;

$\frac{\delta_{u}}{h_{w}}=\varepsilon_{c u}\left(\alpha \frac{t_{w}}{l_{w}} \frac{l_{w}}{c}\right)\left(1-\frac{\alpha}{2} \frac{t_{w}}{h_{w}}\right)+\frac{\varepsilon_{s y}}{\left(1-c / l_{w}\right)}\left(\frac{11}{40} \frac{h_{w}}{l_{w}}-\alpha \frac{t_{w}}{l_{w}}+\alpha \frac{t_{w}}{h_{w}} \frac{t_{w}}{l_{w}}\right)$

where $t_{w}$ is the wall thickness, and $\varepsilon_{s y}$ is the tensile reinforcement yield strain. The constant 11/40 results based on the assumed distribution of lateral force over the height of the wall. ${ }^{68}$ Using Eq. (3), the relationship between the wall neutral axis depth, concrete compressive strain, and drift is computed for various ratios of $l_{w} / t_{w}$ and $h_{w} / l_{w}$ and plastic hinge length. For this preliminary study, wall aspect ratio $h_{w} / l_{w}$ is set to 3.0 and the ratio of $l_{w} / t_{w}$ is set to 13.3 , which is fairly typical for U.S. construction. Concrete compressive strain is set to 0.003; results presented in Fig. 15 for three values of $\alpha(2,6,12)$. For the ratio of $l_{w} / t_{w}$ selected (13.33), $\alpha=6$ is equivalent to $l_{p}=0.45 l_{w}$, or about the same value of $0.5 l_{w}$ assumed in the development of ACI 318-11 relations in Eq. (2). Special transverse reinforcement is required at wall boundaries for values above and to the right of the lines.

According to Fig. 15, if the drift ratio is 0.01 , the neutral axis must exceed $0.17 l_{w}$ before SBEs are required by ACI 318-11. However, for the same neutral axis depth of $0.17 l_{w}$, if inelastic deformations are concentrated over a short height $\left(l_{p}=(\alpha=2) t_{w}\right)$, only less than one-half of this drift ratio $(0.005)$, can be tolerated before SBEs are required. The sensitivity of the results suggests that measures are needed to ensure appropriate spread of plasticity by requiring walls to be tension-controlled or by ductile yielding of concrete in compression for compression-controlled walls. These issues are not currently addressed in ACI 318-11 ${ }^{1}$.

In current US codes the intent is to provide $90 \%$ confidence of non-collapse for MCE shaking. In contrast, the current ACI confinement trigger (Eq. 2) is based on $50 \%$ confidence of not exceeding the concrete crushing limit in the Design Basis Earthquake (which is much lower shaking intensity than the MCE). To address this issue, it is necessary to adjust ACI Equation (21-8), also Eq. (2) in this paper, to be more consistent with the building code performance intent. Three factors need to be considered: 1) 


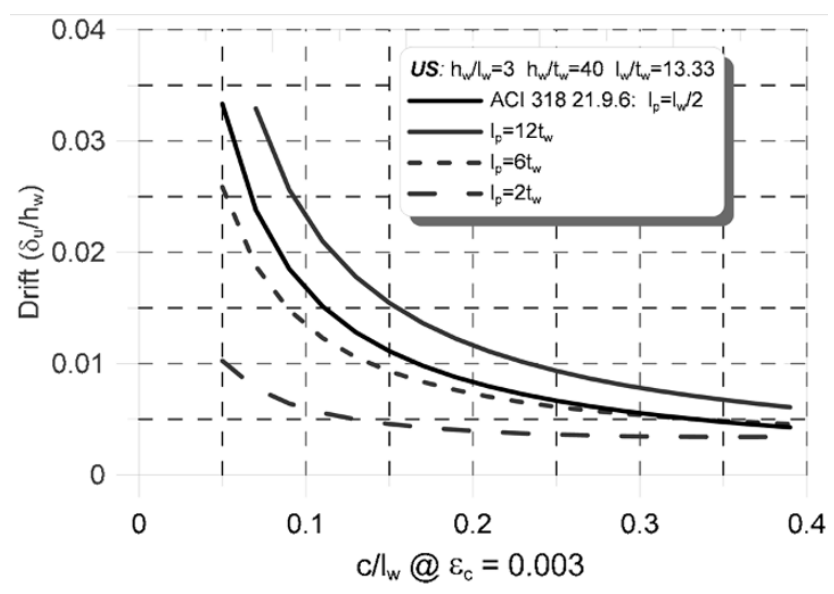

Fig. 15 Influence of plastic hinge length on need for SBEs.

MCE exceeds DBE. 2) There is dispersion about the median response. 3) Damping is likely to be lower than the 5\% value assumed in the ACI provisions. To address these issues, the coefficient of 600 in the denominator of Equation (21-8) in ACI 318-11 ${ }^{1}$ should be increased by a factor of approximately 1.5 to adjust to MCE level shaking and to consider dispersion, and by approximately 1.2 to 1.3 to account for potential lower damping ratios; therefore, a coefficient of 1000 to 1200 should be used as recently recommended in the NIST Technical Brief No. $6 .{ }^{69}$

\subsection{Axial load and compression-controlled walls}

As noted above, the provisions of 318-11 §21.9.6.2 assume that nonlinear deformations within the critical (plastic hinge) region of the wall will spread out over a distance equal to one half the member depth. ACI 318-11 $\$ 9.4$ defines tension- and compressioncontrolled sections; however, no guidance is provided on how these requirements should be applied to special (or ordinary) structural walls. In addition, ACI 318 and ASCE 7 do not place limits on wall axial stress. The performance of walls in Chile suggests that higher axial stresses and wall cross section shape (e.g., Tshaped) may lead to cases where concrete compressive strain reaches 0.003 prior to yield of tension steel.

Various approaches could be used to address this issue, such as placing limit on axial stress or requiring wall critical sections to be tension-controlled. In the 1997 version of the Uniform Building Code, ${ }^{70}$ wall axial load was limited to $0.35 \mathrm{P}_{0}$; for higher axial loads the lateral strength and stiffness of the wall could not be considered. An alternative to neglecting the lateral-force-resistance of compression-controlled walls would be to impose more stringent design requirements, such as always requiring Special Boundary Elements (SBEs) for wall critical sections that are not tension-controlled according to ACI $318-11$ \$9.4, where a section is tensioncontrolled if the reinforcement tensile strain exceeds 0.005 . In addition, it also might be necessary to impose a larger minimum wall thickness $\left(t_{w}\right)$ and a smaller wall slenderness ratio $\left(h_{s} / t_{w}\right)$ for compression-controlled walls. The objective of these requirements would be to maintain a stable compressive zone as the concrete yields in compression.

Even with more stringent design requirements for compressioncontrolled wall sections, it may not be reasonable to expect significant inelastic deformation capacity (rotation) can be achieved through compression yielding of concrete; therefore, it might be prudent to limit the nonlinear deformations. This objective can be accomplished by calculating a limiting drift ratio for a given limit on concrete compressive strain. For an assumed neutral axis depth $c=0.6 l_{w}$ (for balanced failure), a limiting compression strain of 0.01 , Eq. (1) gives: $\delta_{u} / h_{w}<0.010 /(2)(0.6)=0.0083$. Given the simplifying assumptions associated with Eq. (1), a slightly higher drift limit might be appropriate (e.g., $\left.\delta_{u} / h_{w}<0.01\right)$.

\subsection{Boundary element detailing}

ACI 318-11 ${ }^{1}$ detailing requirements for SBEs are based on requirements that were developed for columns; these provisions may be insufficient for thin walls. The review of recent wall damage in earthquakes and laboratory tests provides sufficient evidence to raise concerns related to detailing of thin walls. For example, although the quantity of transverse reinforcement provided at the boundaries of the conventional $\mathrm{RC}$ wall tested at $\mathrm{E}$ Defense were 1.4 and 2.1 times that required by ACI 318-11 $\$ 21.9 .6 .4$ (for the larger spacing of $100 \mathrm{~mm}$ used at Axis C), concrete crushing and lateral instability (Fig. 7(b)) occurred earlier in the Kobe $100 \%$ test, followed by substantial sliding (Fig. 8). Inspection of the damaged boundary zone revealed that relatively large clear cover was used, on the order of $40 \mathrm{~mm}$ (larger than the code minimum in ACI 318, which is $19 \mathrm{~mm}$ ), suggesting that the confined core was incapable of maintaining stability of the compression zone following loss of concrete cover. For columns, ACI 318-11 Equation (21-4), which is based on maintaining column axial load capacity after cover concrete spalling, typically governs the selection of transverse reinforcement for smaller columns where cover makes up a larger percentage of the gross concrete section. This equation also was required for wall SBEs prior to ACI $318-99^{71}$; it was dropped because it rarely controlled for the thicker walls that were commonly used at that time. For the EDefense conventional RC wall, the provided transverse reinforcement is only 0.34 and 0.45 times that required by ACI 318-11 Equation (21-4), suggesting that improved performance may have resulted had this relation been required. Additional testing is needed to determine if reinstating (21-4) is sufficient to ensure ductile behavior of thin boundary zones.

ACI 318-11 \$21.6.6.2 allows a distance of 14” (356 mm) between adjacent hoops or ties. Use of such a large spacing for thin SBEs is unlikely to provide sufficient confinement (Fig. 16) and use of such a large horizontal dimension is incompatible with use of a vertical spacing one-third the wall thickness. For example, for a $10 \mathrm{in} .(254 \mathrm{~mm})$ thick wall, such as used in the E-Defense test, SBE vertical spacing is limited to 3.33 " (84.6 mm); however, the horizontal spacing along the wall can reach $14 \mathrm{in.}(356 \mathrm{~mm})$; therefore, the ratio of vertical to horizontal spacing can reach 14/ $3.33=4.2$. An additional limit should be considered for wall SBEs, similar to that used for vertical spacing, where the horizontal spacing between legs of hoops or ties along the length of the wall is limited to a fraction of the wall thickness, e.g., $0.67 t_{w}$. As well, use of unsupported bars at the wall edge, which initiated the section failure for test PW2 (Fig. 6(a)), should not be allowed until more information is available to justify this detail.

Most of the issues raised in the preceding paragraphs are currently under study by ACI Committee 318 with potential changes being introduced in ACI 318-14. 


\subsection{Wall slenderness and lateral stability}

Limits on wall slenderness should be considered to address instability failures, similar to what was done in the UBC (1997), which imposed a slenderness limit of $t_{w} \geq h_{s} / 16$, where $h_{s}$ is the unsupported height (typically, one story). Based on observations in recent earthquakes and tests, a lower limit should probably be used within plastic hinge zone, a ratio of $t_{w} \geq h_{s} / 10$ was recently recommended in Moehle et al. ${ }^{66}$ This issue is currently under study by ATC $94{ }^{42}$

\section{Wall and coupling beam modeling}

Use of beam-column models with rigid-plastic hinges and fiber models with uniaxial material relations for concrete and reinforcement have become very common for analysis and design of buildings. For coupling beams, a beam-column model is common used, since the added complexity of using a fiber model is generally not warranted, especially for diagonally-reinforced coupling beams. For a fiber model, the cross section geometry is prescribed with concrete and steel fibers and elements are stacked to enable modeling of an element (e.g., planar wall). For fiber models, it is important to use sufficient fibers to define the strain gradient at equilibrium for a given loading and sufficient elements over the wall height to capture the overall wall behavior; however, use of too many fibers and elements may substantially increase computer run time and lead to convergence issues. Although axial-bending $(P-M)$ interaction can be accounted for with beam-column models, typically a discrete bending stiffness must be specified; whereas, for a fiber model, the flexural stiffness and section axialbending strength are derived from the specified material relations and vary depending on the magnitude of axial load. Monitored response quantities are plastic rotations for beam-column models and average strain, curvature, or rotation over a specified element or gage length for fiber models, since use of small element lengths may lead to strain concentration and spurious results. Element or gage lengths are typically selected based on assumed spread of plasticity; use of half the member depth for structural walls is common, although this value may not be appropriate for some cases, as noted in the review of recent test results. Acceptance criteria are typically based on rotation or strain limits derived from test results or engineering judgment, e.g., as given in ASCE 41$06^{72}$ Tables 6-18 and 6-19, and $\S 6.4 .3 .1$ sets the maximum permissible strain limits.

Comparisons between analytical and experimental results for structural walls using simple beam-column and fiber models have been reported by various researchers, including Thomsen and Wallace, ${ }^{41}$ Wallace $1{ }^{73}$ Elwood et al., ${ }^{36}$ Orakcal and Wallace, ${ }^{6}$ and PEER/ATC-72. ${ }^{74}$ The focus here is on the comparisons for fiber

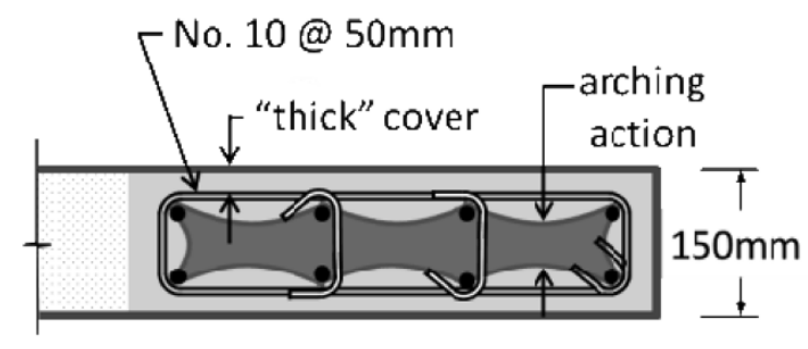

Fig. 16 Confinement of thin wall sections. models, such as given in Fig. 17, ${ }^{6}$ which reveal that fiber models using fairly sophisticated uniaxial material models are capable of capturing load versus top displacement measured for flexural deformations in laboratory tests for low-to-moderate axial stress levels $P=0.10 A_{g} f_{c}^{\prime}$. It is noted that the model is not capable of capturing strength degradation due to rebar buckling and rebar fracture; therefore, the strength degradation that initiates under positive load at the end of the test is not captured by the model. Comparisons between model and test results for a wall with a Tshaped cross-section (Fig. 17(b)) indicate that the overall load-displacement response is reasonably captured, although the model slightly over-predicts the wall strength for the flange in tension. The likely reason for this discrepancy is the inability of the model to capture the nonlinear tensile strain variation in the flange, ${ }^{74}$ since the model assumes the same strain gradient (plane sections remain plane) for the web and the flange. Waugh and Sritharan ${ }^{51}$ investigated the use of a modified fiber model to address this issue, and report moderately improved comparisons, although the model is limited to two-dimensional analysis. Orakcal and Wallace ${ }^{6}$ also report that fiber models are capable of capturing local responses, such as base rotation, average curvature, and average strains. Given that fiber models use uniaxial material models for assumed plane sections, the results indicate that moment curvature analysis is an appropriate tool for assessing the stiffness and strength, and to a lesser degree, deformation capacity, of slender walls. This observation is supported by findings reported in PEER/ATC- $72^{74}$ and Johnson. ${ }^{33}$

The results presented in Fig. 17 compare nonlinear flexural deformations obtained from the test and from the model, i.e., the test data were processed to separate deformations due to flexure and shear using the procedure recommended by Massone and Wallace. ${ }^{15}$ Analysis results for wall RW2 using a coupled model, or shear-flexure interaction model ${ }^{17}$ are shown in Fig. 18 for two monotonic (pushover) analyses. For the first analysis, a monotonic steel stress - strain relation was used, whereas in the second analysis, the steel stress - strain relation was manipulated to approximate the impact of cyclic loading (since the coupled model used did not have cyclic material models). It is noted that the manipulated cyclic analysis results more closely match the test results and are consistent with results presented in Fig. 14(a). Strain profiles for the coupled model at three drift ratios are compared with test results (Fig. 18(b)) and indicate that larger compressive strains are predicted with the model compared with an uncoupled model. ${ }^{6}$ Johnson ${ }^{53}$ reports similar observations. The findings suggest that coupling (shear-flexure interaction) leads to significantly larger concrete compressive strains than would be predicted using an uncoupled model. Although the results presented here are preliminary, they indicate that the larger compressive strains measured in the tests are likely related to physical phenomena; therefore, they cannot be discounted. An alternative (uncoupled) modeling approach, where the shear force-deformation behavior is softened to account for nonlinear shear deformations, is presented in ATC$76^{75}$; however, this modeling approach does not account for the impact of shear-flexure interaction on concrete compressive strain, it only addresses the underestimation of lateral deformations. Since the approach used in ACI 318-11 §21.9.6.2 to assess detailing requirements (presented earlier) is based on estimating the concrete compressive strain, the likely under-estimation of con- 

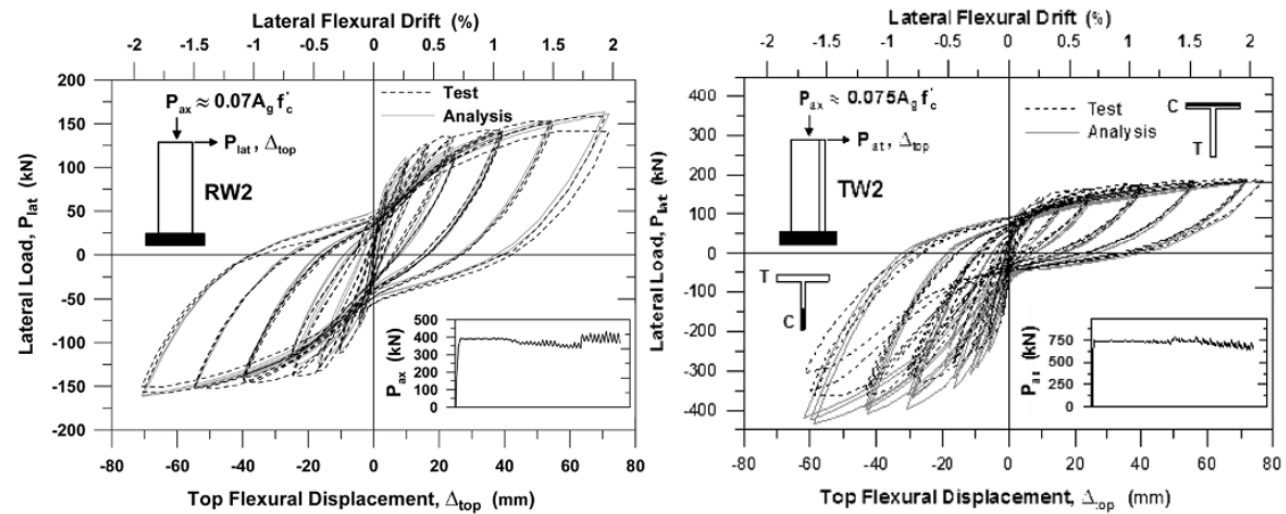

Fig. 17 Comparison of model and test results ${ }^{6}$.

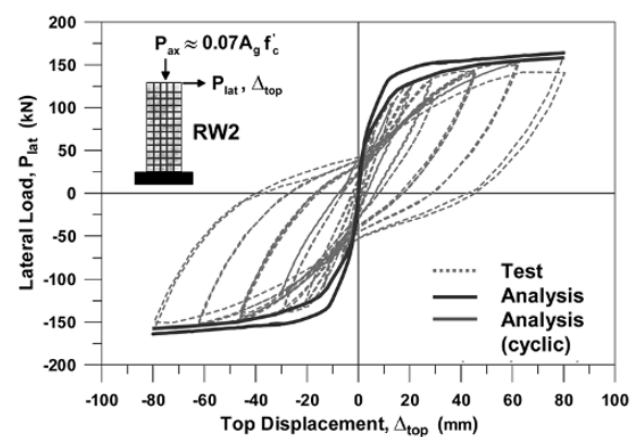

(a) Load-displacmenet

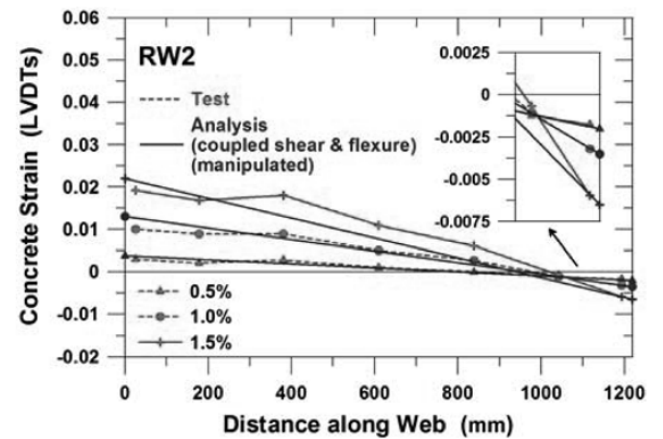

(b) curvature

Fig. 18 Shear-flexure interaction model: (a) Load-displacement; (b) curvature.

crete compressive strain due to shear-flexure interaction should be considered (indirectly, probably via the coefficient in ACI 318-11 Equation 21-8). Clearly, this is an area that requires additional research.

The results presented here and the other studies noted do indicate that fiber models (and beam-column models) are valuable design tools provided that the one understands that the results obtained are not precise, i.e., the sensitivity of the results are considered. For example, local responses are more likely to be sensitive to model (e.g., mesh) and material (e.g., reinforcement strain hardening) parameters, ${ }^{2,74,75}$ and studies indicate that concrete compressive strains are generally under-estimated (unless shearflexure interaction is considered).

It also is important to note that the studies summarized here do not address modeling of splice behavior (anchorage slip/extension, sometimes referred to as strain penetration, has been studied) and sliding shear behavior. As discussed in the review of recent tests, splice behavior significantly impacted wall deformations capacity, focusing inelastic deformations either below (Fig. 4(b)) or above (Fig. 5(b), Fig. 6) the splice region, whereas concrete crushing and rebar buckling at the wall boundary for the E-Defense test led to large sliding shear deformations (Fig. 8(b)). Although it is possible to incorporate these behaviors into fiber models, insufficient test data exist to calibrate and validate these models. As well, even with test data, it is questionable whether modeling these behaviors is recommended. At least for new design, it is probably advisable to avoid these problems, although additional testing is needed to better determine how to accomplish this goal.

\subsection{Coupling beams}

Nonlinear modeling approaches commonly used by practicing engineers are investigated to assess how well they are able to represent the measured test results presented earlier. Two models are considered, one utilizing a rotational spring at the ends of the beam to account for both nonlinear flexural and shear deformations $\left(M_{n}\right.$ hinge) and one utilizing a nonlinear shear-displacement spring at beam mid-span to account for both shear and shear deformations $\left(V_{n}\right.$ hinge). Both models were subjected to the same loading protocol used in the tests. ${ }^{31}$ In this study, CSI Perform 3D was used. ${ }^{76}$ Naish $^{31}$ provides detailed information on modeling parameters used to generate analysis results. Backbone relations for the models were derived from test results, described below.

\subsection{Test backbone relations}

Backbone relations derived from the test data (solid line) are compared with the original unmodified test backbone relations (broken lines) and ASCE $41^{72}$ relations (wide line) in Fig. 19. The test relations were modified because slip/extension deformations, which were significant for the one-half scale tests, produce less beam chord rotation for full-scale beams. The ASCE $41^{72}$ relation, primarily based on test results for coupling beams with aspect ratio less than 1.5 , is too stiff. Naish ${ }^{31}$ reassessed the relation used for low aspect ratio coupling beams using fragility relations, and recommends new, slightly modified relations.

\subsection{Diagonally-reinforced coupling beams $(2.0<$ $\left.I_{n} / h<4.0\right)$}

The $M_{n}$-hinge model consists of an elastic beam cross-section 
with $E_{c} I_{\text {eff }}=0.5 E_{c} I_{g}$, elastic-rotation springs (hinges) at each beamend to simulate the effects of reinforcement slip/extension deformations, and rigid plastic rotational springs (hinges) at each beamend to simulate the effects of nonlinear deformations. The stiffness of the slip/extension hinges are defined using the Alsiwat and Saatcioglu ${ }^{77}$ model, whereas the plastic rotations of the nonlinear flexural hinges are modeled using the backbone relations derived from test results (Fig. 19, for original test data, but excluding the elastic deformation) with nominal shear strength defined using ACI 318-08 Equation (21-9). The $V_{n}$-hinge model also consists of an elastic beam cross-section and slip/extension hinges; however, instead of using flexural hinges at the beam ends, a shear force versus displacement hinge (spring) is used at beam mid-span to simulate the effects of nonlinear deformations. The shear hinge properties are defined using the backbone relations derived from the test results (Fig. 19, for original test data).

Figure 20 shows cyclic load-deformation plots for the two models and the test results for CB24F, which are representative of results obtained for other specimens. Both models accurately capture the overall load-displacement response of the member; however, the $M_{n}$-hinge model (Fig. 20(a)) captures the unloading characteristics better than the $V_{n}$-hinge model (Fig. 20(b)), due to the fact that unloading stiffness modeling parameters, which help to adjust the slope of the unloading curve, are available for the flexural hinges in the commercial computer program used, but not for the shear hinges (see Naish ${ }^{31}$ for a complete description of the modeling parameters and assigned values).

Model results for two frame beam tests are shown in Fig. 13 for the $M_{n}$ hinge model, again using the CSI Perform $3 \mathrm{D}^{76}$ program. The models accurately capture the measured responses, specifi-

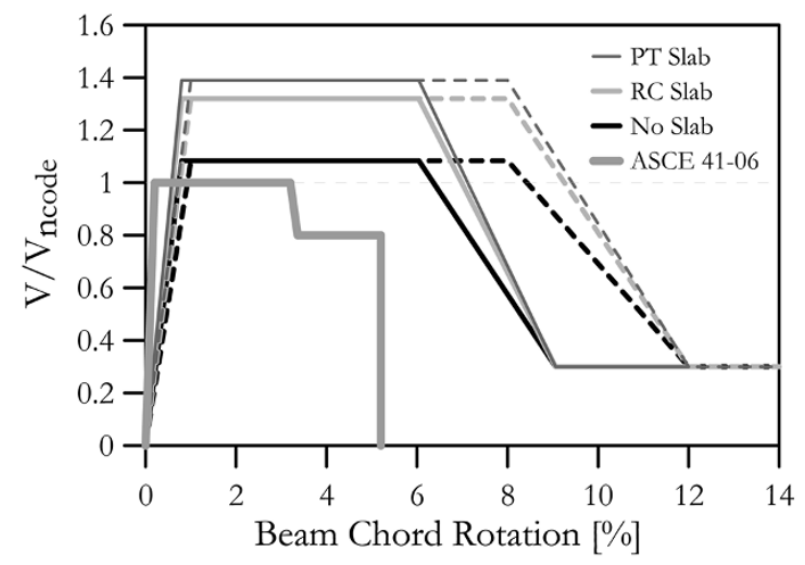

Fig. 19 Coupling beam test backbone curves. cally in the slope of the loading and unloading curves, and in the pronounced pinching of the cyclic load-deformation plot. The commercial computer program used allowed the shape of the load-deformation loops to be manipulated through specifying energy dissipation parameters to simulate the pinching of the loaddeformation plots of the test beams. Naish ${ }^{31}$ includes detailed information on the model parameters used in the comparisons.

\section{Conclusions}

Wall performance in recent earthquakes and laboratory tests is reviewed and American Concrete Institute 318 provisions are reassessed to identify possible shortcomings. The findings suggest a number of issues require more in-depth study, particularly for thin walls. Approaches that could be implemented within ACI 318 to address these issues also are presented. In particular, changes are needed to increase the design displacement used in ACI 31811 Equation (21-8), changing the value of the denominator from 600 to 1200 is recommended. To ensure spread of plasticity consistent with the derivation of Equation (21-8), walls should be tension-controlled or be designed and detailed to maintain a stable compressive zone as the concrete yields in compression. Limits on wall thickness and slenderness are suggested as one way of addressing this latter issue. Limiting wall compression strain for compression-controlled walls also might be prudent; this can be accomplished by limiting the drift ratio to about 0.01 .

Recent tests of 2.4 and 3.33 aspect ratio coupling beams are presented and reveal that beams detailed according to the new provision in ACI 318-08, which allow for full section confinement, have performance, in terms of strength and ductility, that is slightly better than beams detailed according to the old provision in ACI 318-05, which requires confinement of the diagonal bar groups. Including a reinforced concrete slab increases the beam shear strength approximately $15-20 \%$, whereas adding post-tensioning increases the beam shear strength an additional $10 \%$. However, the strength increase was directly related to the increase in beam moment strength, as the beam shear force was limited by flexural yielding.

Modeling approaches used for structural walls adequately capture the nonlinear axial-bending responses, but are unable to capture strength loss, which typically results for buckling of vertical boundary reinforcement or lateral instability of the flexural-compression zone. Additional experimental studies are required to better characterize these types of failures, particularly for thin walls. Recent research related to wall modeling has focused on capturing

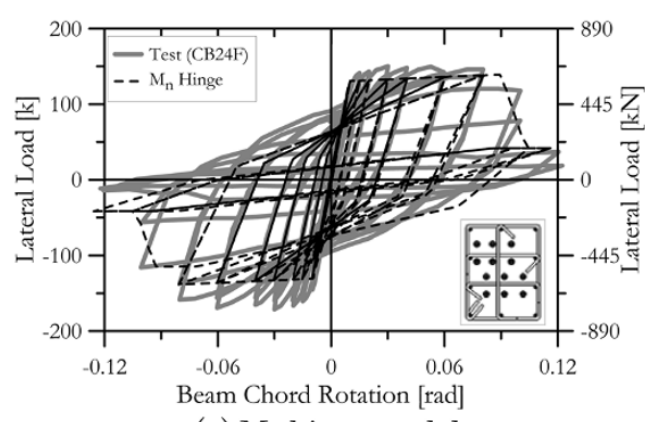

(a) $M_{n}$ hinge model

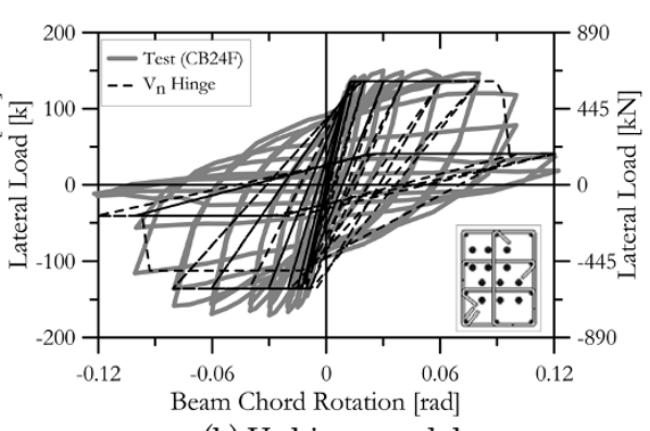

(b) $V_{n}$ hinge model

Fig. 20 Model and test results: (a) $M_{n}$ hinge model; (b) $V_{n}$ hinge model. 
observed shear-flexure interaction, where nonlinear shear deformations are observed for slender walls where behavior is dominated by flexural responses. A variety of modeling approaches have recently been proposed using biaxial material models, truss models, and empirical approaches. Available information strongly suggests that shear-flexure interaction leads to large concrete compressive strains than would be predicted with an uncoupled model, suggesting that current ACI 318 provisions that base wall boundary detailing requirements on concrete compressive strain should include a measure of conservatism until this behavior is better understood. Additional research, including detailed experimental measurements of global and local responses, is needed to validate and calibrate models for cyclic loads and for cases where nonlinear shear deformations are more significant (typically aspect ratio 1.5 to 3.0 walls).

Simple nonlinear model approaches for coupling beams, either moment-hinge or shear-hinge, accurately represent the load-deformation behavior of test beams. The flexural hinge model better matches the test results in the unloading and reloading range, due to the specific modeling parameters available in the computer software used (unloading stiffness modeling parameters), although both models produce acceptable results up to $3 \%$ total rotation for beams with $l_{n} h$ between 2.0 and 4.0. Therefore, depending on the computer program used, the influence of modeling parameters on the load versus deformation responses should be compared with test results to ensure that they adequately represent observed behavior.

\section{Acknowledgements}

This research described in this paper was carried out with funding from various sources, including the EERI Learning from Earthquakes program (NSF CMMI-0758529), NSF RAPID projects to enhance US-Japan collaboration related to the EDefense tests in December 2010 (CMMI-1110860 and CMMI1000268; Program Director Joy Pauschke), NSF NEES REU (CMMI-0927178), Charles Pankow Foundation (CPF Grant No. 4-06), as well as support provided to the first author by the Japan Society for the Promotion of Science (JSPS) Invitation Fellowship Program during the fall 2010. This support is gratefully acknowledged. The author would like to thank those researchers who have contributed their research results to NEEShub, which provides an invaluable resource, as well as other researchers for their comments and input, including C French (U Minnesota), S. Sritharan (Iowa State), L Lowes and D Lehman (U Washington), K Elwood (UBC), and J Moehle (UC Berkeley). And finally, the author would like to express his deep appreciation to the Japanese researchers involved with the December 2010 E-Defense tests for sharing their research ideas and results, including: $\mathrm{T}$ Nagae (NIED), K Tahara (NIED), T Matsumori (NIED), H Shiohara (U Tokyo), T Kabeyasawa (U Tokyo ERI), S Kono (Kyoto U), M Nishiyama (Kyoto U); and M. Nakashima (NIED, Kyoto U). Opinions, findings, conclusions, and recommendations in this paper are those of the author, and do not necessarily represent those of the sponsors or other individuals mentioned here.

\section{References}

1. American Concrete Institute. Building Code Requirements for Structural Concrete (ACI 318-11) and Commentary (ACI 318R-11), Farmington Hills, Michigan, 2011.

2. Orakcal, K., Conte, J. P., and Wallace, J. W., "Flexural Modeling of Reinforced Concrete Walls - Model Attributes," ACI Structural Journal, Vol. 101, No. 5, 2004, pp. 688 698.

3. Kabeyasawa, T., Shiohara, H., Otani, S., and Aoyama, H., "Analysis of the Full-Scale Seven-Story Reinforced Concrete Test Structure", Journal of the Faculty of Engineering, The University of Tokyo (B), Vol. 37, No. 2, 1983, pp. 431 478.

4. Fischinger, M., Vidic, T., Selih, J., Fajfar, P., Zhang. H. Y., and Damjanic, F. B., "Validation of a Macroscopic Model for Cyclic Response Prediction of RC Walls," in N.B. Bicanic and H. Mang (eds.), "Computer Aided Analysis and Design of Concrete Structures," Pineridge Press, Swansea, Vol. 2, 1990, pp. $1131 \sim 1142$.

5. Colotti, V., "Shear Behavior of RC Structural Walls," Journal of Structural Engineering, ASCE, Vol. 119, No. 3, 1993, pp. 728 746.

6. Orakcal, K. and Wallace, J. W., "Flexural Modeling of Reinforced Concrete Walls - Model Calibration," ACI Structural Journal, Vol. 103, No. 2, 2006, pp. 196 206.

7. Massone, L. M., Orakcal, K., and Wallace, J. W., "Modeling of Squat Structural Walls Controlled by Shear," ACI Structural Journal, Vol. 106, No. 5, 2009, pp 646 655.

8. Limkatanyu, S. and Spacone, E., "Reinforced Concrete Frame Element with Bond Interfaces. I: Displacement-Based, Force-Based, and Mixed Formulations," J. Struct. Eng., Vol. 128, 2002, 346 pp.

9. Elwood, K. J. and Moehle, J. P., "Axial Capacity Model for Shear-Damaged Columns," Structural Journal, ACI, Vol. 102, No. 4, 2005, pp. 578 587.

10. Elwood, K. J. and Moehle, J. P., "Dynamic collapse analysis for a reinforced concrete frame sustaining shear and axial failures," Earthquake Engineering and Structural Dynamics, Vol. 37, No. 7, 2008, pp. 991 1012.

11. Wallace, J. W., Elwood, K. J., and Massone, L. M., "An Axial Load Capacity Model for Shear Critical RC Wall Piers," Journal of Structural Engineering, ASCE, Vol. 134, No. 9, 2008, pp. $1548 \sim 1557$.

12. Oesterle, R. G., Fiorato, A. E., Johal, L. S., Carpenter, J. E., Russell, H. G., and Corley, W. G., "Earthquake Resistant Structural Walls - Test of Isolated Walls," Report No. GI-43880/ RA-760815, National Science Foundation, Arlington, Va., 1976, $315 \mathrm{pp}$.

13. Oesterle, R. G., Aristizabal-Ochoa, J. D., Fiorato, A. E., Russell, H. G., and Corley, W. G., "Earthquake Resistant Structural Walls - Test of Isolated Walls - Phase II," Report No. ENV77-15333, National Science Foundation, Arlington, Va., 1979, 327 pp.

14. Hiraishi, H., "Evaluation of Shear and Flexural Deformations of Flexural Type Shear Walls," Bulletin of the New Zealand National Society for Earthquake Engineering, Vol. 17, No. 2, 1984, pp. 135-144.

15. Massone, L. M. and Wallace, J. W., "Load - Deformation responses of Slender Reinforced Concrete Walls," ACI Structural Journal, Vol. 101, No. 1, 2004, pp. 103 113.

16. Petrangeli, M., Pinto, P. E., and Ciampi, V., "Fiber Element for Cyclic Bending and Shear of RC Structures. I: The- 
ory", Journal of Engineering Mechanics, ASCE, Vol. 125, No. 9, 1999, pp. 994 1001.

17. Massone, L. M., Orakcal, K., and Wallace, J. W., "Modeling flexural/shear interaction in RC walls, ACI-SP-236, Deformation Capacity and Shear Strength of Reinforced Concrete Members under Cyclic Loadings, American Concrete Institute," Farmington Hills, MI, Paper 7, 2006, pp. 127 150.

18. Jiang, H. and Kurama, Y. C., "Analytical Modeling of Medium-Rise Reinforced Concrete Shear Walls", ACI Structural Journal, Vol. 107, No. 4, 2010, pp. 400 410.

19. Panagiotou, M. and Restrepo, J. I., (2011), "Nonlinear Cyclic Truss Model for Strength Degrading Reinforced Concrete Plane Stress Elements," Report No. UCB/SEMM-2011/01, Structural Engineering, Mechanics and Materials, Department of Civil and Environmental Engineering University of California, Berkeley, 37 pp., February 2011.

20. Xu, S.-Y. and Zhang, J., "Hysteretic shear-flexure interaction model of reinforced concrete columns for seismic response assessment of bridges," Earthquake Engng Struct. Dyn., Vol. 40, No.3, 2011, pp. 315 337.

21. Beyer, K., Dazio, A., and Priestley, M. J. N., "Shear deformations of slender reinforced concrete walls undet seismic loading”, ACI Structural Journal, Vol. 108, No. 2, 2011, pp. 167 177.

22. Trna, T. A. and Wallace, J. W. "Lateral Load Behavior of Moderate Aspect Ratio RC Structural Walls," PhA Prospectus, University of California, Los Angeles, Department of Civil Engineering, 2010, 62 pp.

23. Paulay, T., "Coupling Beams of Reinforced Concrete Shear Walls," Journal of Structural Division, ASCE, 1971, pp. 843 862.

24. Paulay, T. and Binney, J. R., "Diagonally Reinforced Coupling Beams of Shear Walls," Shear in Reinforced Concrete, SP42, American Concrete Institute, Farmington Hills, Mich., 1974, pp. 579 598.

25. Barney, G. B., Shiu, K. N., Rabbit, B. G., Fiorato, A. E., Russell, H. G., and Corley, W. G., "Behavior of Coupling Beams under Load Reversals (RD068.01B)," Portland Cement Association, Skokie, IL, 1980.

26. Tassios, T. P., Moretti, M., and Bezas, A., "On the Coupling Behavior and Ductility of Reinforced Concrete Coupling Beams of Shear Walls," ACI Structural Journal, Vol. 93, No. 6, 1996, pp. 711 720.

27. Xiao, Y., Esmaeily-Ghasemabadi, A., and Wu, H., "HighStrength Concrete Beams Subjected to Cyclic Shear," ACI Structural Journal, Vol. 96 No.3, 1999, pp.392 399.

28. Galano, L. and Vignoli, A., "Seismic Behavior of Short Coupling Beams with Different Reinforcement Layouts," ACI Structural Journal, Vol. 97, No. 6, 2000, pp. 876 885.

29. Kwan, A. K. H. and Zhao, Z. Z., "Testing of coupling beams with equal end rotations maintained and local joint deformation allowed," Structures and Buildings, Thomas Telford, London, Vol. 152, No. 1, 2001, pp. 67 78.

30. Fortney, P., "The Next Generation of Coupling Beams," PhD Dissertation, University of Cincinnati, 2005, 370 pp.

31. Naish, D., "Testing and Modeling of Reinforced Concrete Coupling Beams", Ph.D. Dissertation, Department of Civil \& Environmental Engineering, University of California, Los Angeles, CA, 2010, 251 pp.

32. Naish, D. and Wallace, J. W., "Testing and Modeling of
Diagonally-Reinforced Reinforced Concrete Coupling Beams," Proceedings Special Session, 9th U.S. National Conference on Earthquake Engineering, Toronto, Canada, 2010 (Paper 1575).

33. Parra-Montesinos, G., Wight, J. K., Lequesne, R. D., and Seekit, M., "A summary of ten years of research on HPFRC coupling beams," High Performance Fiber Reinforced Cement Composites 6, Parra-Montesinos, Gustavo J., Reinhardt, Hans W., Naaman, Antoine E. (Ed.), 2012, 560 pp.

34. Wallace, J. W., "Modeling Issues for Tall Reinforced Concrete Core Wall Buildings," The Structural Design of Tall and Special Buildings, Wiley InterScience, Vol. 16, 2007, pp. 615 632.

35. Wallace, J. W., "Performance-Based Design of Tall Core Wall Buildings," Earthquake Engineering in Europe, Garevski M and Ansal A, editors, Springer, 2010, pp. 279 307.

36. Elwood, K. J., Matamoros, A. B., Wallace, J. W., Lehman, D. E., Heintz, J. A., Mitchell, A. D., Moore, M. A., Valley, M. T., Lowes, L. N., Comartin, C. D., and Moehle, J. P., "Update to ASCE/SEI 41 Concrete Provisions," Earthquake Spectra, Vol. 23, No. 3, 2007, pp. 493 523.

37. NCh 433.Of 96, Diseño Sismico de Edificios (Chilean Building Code), Chile, 2006.

38. American Concrete Institute. Building Code Requirements for Structural Concrete (ACI 318-95) and Commentary (ACI 318R-95), Farmington Hills, MI, 1995.

39. Wallace, J. W., "February 27, 2010 Chile Earthquake: Preliminary Observations on Structural Performance and Implications for U.S. Building Codes and Standards," ASCE Structures Congress, Paper 1159, Las Vegas, 2011.

40. Massone, L. M. and Wallace, J. W., "Lessons from Chile: Impacts of Earthquake Engineering of RC Buildings in the US," EERI/NEES Webinar, 2011. http://nees.org/resources/3192

41. Thomsen, I. V., Wallace, J. H., and Wallace, J. W., "Displacement-Based Design of Slender RC Structural Walls - Experimental Verification," J. Struct. Eng., ASCE, Vol. 130, No. 4, 2004, pp 618 630.

42. ATC-94, "Analysis of Seismic Performance of Reinforced Concrete Buildings in the 2010 Chile Earthquake, Including Effects of Non-Seismic-Force-Resisting Building Structural Elements - Task Order 21", 2011. https://www.atcouncil.org/Projects/ nehrp-jv.html

43. Corley, W. G., Fiorato, A. E., and Oesterle, R. G., "Structural Walls," Publication SP-72, ACI, 1981, pp. 77 131.

44. Paulay, T. and Priestley, M. J. N., "Stability of Ductile Structural Walls," ACI Structural Journal, American Concrete Institute, Vol. 90, No. 4, 1993, pp. 385 392.

45. Chai, Y. H. and Elayer, D. T., "Lateral Stability of Reinforced Concrete Columns under Axial Reversed Cyclic Tension and Compression," ACI Structural Journal, ACI, Vol. 96, No. 5, 1999, pp. 780 789.

46. EERI, "The M 6.3 Christchurch, New Zealand, Earthquake of February 22, 2011," EERI Special Earthquake Report, 2011.

47. NZRC, "Canterbury Earthquakes Royal Commission Interim Report," 2011. http://canterbury.royalcommission.govt.nz/ Interim-Report.

48. Wallace, J. W., "Evaluation of UBC-94 Provisions for Seismic Design of RC Structural Walls," Earthquake Spectra, 
Vol. 12, No. 2, 1996, pp. 327 348.

49. Elwood, K. J., Personal Communication. [see Also EERI Christchurch Earthquake Clearing House, 2011: http://www.eq clearinghouse.org/2011-02-22-christchurch/

50. Waugh, J., Aaleti, S., Sritharan, S., and Zhao, J., "Nonlinear Analysis of Rectangular and T-Shaped Concrete Walls," ISU-ERI-Ames Report ERI-09327, Iowa State University, Department of Civil, Construction and Environmental Engineering, 2008, $351 \mathrm{pp}$.

51. Waugh, J. D. and Sritharan, S., "Nonlinear Analysis of TShaped Concrete Walls Subjected to Multi-Directional Loading, Proceedings Paper 1506, 9th U.S. National Conference and 10th Canadian Conference on Earthquake Engineering, Ontario, Canada, 2010.

52. Brueggen, B. L. and French, C. W., "Simplified Modeling of Non-Rectangular RC Structural Walls," Proceedings Paper 1713, 9th U.S. National Conference and 10th Canadian Conference on Earthquake Engineering, Ontario, Canada, 2010.

53. Open System for Earthquake Engineering Simulation (OpenSees), Pacific Earthquake Engineering Research Center, University of California, Berkeley, 2009. http://opensees.berkeley.edu/

54. Birely, A., Lehman, D., Lowes, L., Kuchma, D., Hart, C., and Marley, K., "Investigation of the Seismic Response of Planar Concrete Walls," Proceedings Paper 773, 9th U.S. National Conference and 10th Canadian Conference on Earthquake Engineering, Ontario, Canada, 2010.

55. Birely, A., Lehman, D., Lowes, L., Kuchma, D., Hart, C., and Marley, K., "Investigation of the Seismic Behavior and Analysis of Reinforced Concrete Structural Walls," Proceedings 14th World Conference on Earthquake Engineering, Beijing, China, 2008.

56. Sriram, A. and Sritharan, S., "Nonlinear Fiber-Based Analysis of Rectangualr Concrete Walls Designed with Different Anchorage Details,", Proceedings Paper 123, 9th U.S. National Conference and 10th Canadian Conference on Earthquake Engineering, Ontario, Canada, 2010.

57. Lehman, D. E. and Lowes, L. N., "Personal communication about laboratory test results for NEESR project Seismic Behavior, Analysis, and Design of Complex Wall Systems," 2011. see also nees.org/warehouse/project/104

58. Panagiotou, M. and Restrepo, J. I., "Practical Lessons Learned from the Full-Scale 7-Story Building Shake Table Test at UC San Diego," 2007 SEAOC Convention, Squaw Creek, CA, 2007, pp. 57 74.

59. Kabeyasawa, T., Kabeyasawa, T., Matcumori, T., Kabeyasawa, T. and Kim, Y., "Full-scale dynamic collapse tests of three-story reinforced concrete buildings on flexible foundation at E-defense," Proceedings of the 14th World Conference on Earthquake Engineering, Beijing, China, Paper ID: S15-002, 2008.

60. Kabeyasawa, T., Kabeyasawa, T., and Kim Y., "Collapse Simulation of Reinforced Concrete Buildings with ASFI Approach, Proceedings Paper 816, 9th U.S. National Conference and 10th Canadian Conference on Earthquake Engineering, Ontario, Canada, 2010.

61. Kabeyasawa, T., Kabeyasawa, T., Kim, Y., Kabeyasawa, T., Bae, K., and Quang, P. V., "Strength and Deformability of
Reinforced Concrete Columns with Wing Walls," Proceedings Paper 813, 9th U.S. National Conference and 10th Canadian Conference on Earthquake Engineering, Ontario, Canada, $2010 \mathrm{~b}$. 62. Nagae, T., Tahara, K., Matsumori, T., Shiohara, H., Kabeyasawa, T., Kono, S., Nishiyama, M. Wallace, J. W., Ghannoum, W., Moehle, J. P., Sause, R., Keller, W., and Tuna, Z., "Design and Instrumentation of the 2010 E-Defense Four-Story Reinforced Concrete and Post-Tensioned Concrete Buildings," Report No 2011-XX, Pacific Earthquake Engineering Research Center, Department of Civil \& Environmental Engineering, University of Califoria, Berkeley, 2011, 235 pp.

63. Brueggen, B. L., "Performance of T-shaped Reinforced Concrete Structural Walls under Multi-Directional Loading," PhD Dissertation, University of Minnesota, Department of Civil Engineering, 2009, 498 pp.

64. Boroschek, R., Soto, P., and Leon, R., "Registros del Terremoto del Maule $\mathrm{M}_{\mathrm{w}}=8.827$ de Febrero de 2010," Red Nacional de Acelerógrafos del Departamento de Ingeniería Civil, Facultad de Ciencias Físicas y Matemáticas, Universidad de Chile, Informe RENADIC 10/05, 2010, 100 pp. (http://www.terremotosuchile.cl/)

65. Naish, D., Wallace, J., Fry, J. A., and Klemencic, R., "Experimental Evaluation and Analytical Modeling of ACI 31805/08 Reinforced Concrete Coupling Beams Subjected to Reversed Cyclic Loading”, Report No. UCLA-SGEL 2009/06, 2009.

66. Moehle, J. P., Acevedo, C., and Creagh, A., "Exploratory tests of wall boundary elements subjected to alternating tensile and compressive loadings," Poster and oral presentations at 2010 PEER Annual Meeting, 2011.

67. Wallace, J. W. and Orakcal, K., "ACI 318-99 Provisions for Seismic Design of Structural Walls," ACI Structural Journal, American Concrete Institute, Vol. 99, No. 4, 2002, pp. 499 508.

68. Wallace, J. W. and Moehle, J. P., "Ductility and Detailing Requirements of Bearing Wall Buildings," J. Struct. Eng., ASCE, Vol. 118, No. 6, 1992, pp.1625 1644.

69. Moehle, J. P., Ghodsi, T., Hooper, J. D., Fields, D. C., and Gedhada, R., "Seismic Design of Cast-in-Place Concrete Special Structural Walls and Coupling Beams: A guide for practicing engineers," NEHRP Seismic Design Technical Brief No. 6, National Institute of Standards and Technology, Gaithersburg, MD, 2011.

70. UBC, Uniform Building Code, International Council of Building Code Officials, Whittier, CA, 1997.

71. American Concrete Institute. Building Code Requirements for Structural Concrete (ACI 318-99) and Commentary (ACI 318R-99), Farmington Hills, MI, 1999.

72. American Society of Civil Engineers, "ASCE/SEI Standard 41-06, Seismic Rehabilitation of Existing Buildings," Reston, VA, 2007, 428 pp.

73. Wallace, J. W., "Slender Wall Behavior and Modeling," PEER/EERI Technical Seminar Series, New Information on the Seismic Performance of Existing Concrete Buildings, 2006. see www.eeri.org/

74. PEER/ATC-72-1, "Modeling and acceptance criteria for seismic design and analysis of tall buildings," Applied Technology Council, 2010, 242 pp.

75. ATC-76, NIST GCR 10-917-08 (2012), "Evaluation of 
the FEMA P-695 Methodology for Quantification of Seismic Performance Factors," 2011. www.nehrp.gov/pdf/nistgcr10-9178.pdf

76. CSI, PERFORM-3D, Computers \& Structures, Inc., Ber- keley, CA, 2009.

77. Alsiwat, J. and Saatcioglu, M. "Reinforcement Anchorage Slip under Monotonic Loading," Journal of Structural Engineering ASCE, Vol. 118, No. 9, 1992, pp. 2421 2438. 